\title{
El comportamiento de las audiencias de televisión en Chile. Estudio sociológico a partir de los datos generados por el sistema People Meter
}

Ignacio Arnold Urzúa. Sociólogo, Pontificia Universidad Católica de Chile. Magíster en Sociología, Pontificia Universidad Católica de Chile.

(iarnold@canal13.cl)

Palabras Clave: Audiencias televisivas/ Medios de Comunicación Masivos/ Televisión/ People Meter/ Estadísticas

\section{Resumen}

Este documento corresponde a un extracto de la tesis para optar al grado de Magíster en Sociología por la Pontificia Universidad Católica de Chile, realizada por Ignacio Arnold Urzúa. En ella se exploran tres dimensiones del consumo televisivo observable que se registró en Chile durante los últimos años: la estructura temporal y horaria de la exposición televisiva, la cuota de audiencia acaparada por los principales canales de la televisión abierta y la herencia de televidentes fieles en programas pareados.

\section{Introducción y fundamentación del estudio}

\subsection{Presentación}

Rating es un vocablo anglosajón que significa clasificación, rango o grado, pero que hoy por hoy suele ser tomado como el índice de audiencia televisiva por excelencia. En efecto, hemos sido testigos de cómo esta palabra foránea ha entrado de lleno en nuestra habla cotidiana y ha acaparado, además, un lugar destacado en las secciones de espectáculos de la prensa escrita. Tanto es así que ya no nos sorprende que se converse coloquialmente sobre los ratings promedio que obtuvieron los programas de la noche anterior o que un periódico publique en su primera plana que determinado canal ha incrementado sus niveles relativos de audiencia.

La popularización de la palabra rating en Chile coincidió con la inauguración, a principios de los noventa, de la medición electrónica del consumo televisivo. A partir de entonces, los canales de televisión, las agencias de publicidad y los avisadores -e indirectamente la prensa escrita y las personas en general- tuvieron la posibilidad de conocer cifras numéricas asociadas al porcentaje de individuos y hogares que sintonizaron determinado programa o franja horaria.

Al igual que en muchos otros países, el comportamiento de las audiencias de televisión es medido aquí de forma electrónica. En Chile se utiliza el sistema People Meter, perteneciente a la empresa Time-lbope. Gracias a este mecanismo, basado en modernos aparatos que se conectan al receptor de un televisor, es posible detectar minuto a minuto las pincipales características de la exposición televisiva de una muestra estable de personas y hogares del Gran Santiago. Actualmente la muestra de observación está compuesta por aproximadamente 450 hogares y 1800 personas. Tras registrar su comportamiento televisivo, cuantificarlo y ponderarlo, se generan las cifras de audiencia total que Time-lbope da a conocer instantáneamente (provisorias) o con un día de retraso (definitivas). Sobre la base de estos índices, los agentes interesados estiman los comportamientos del total de los televidentes y, de paso, toman importantes decisiones programáticas y de inversión publicitaria.

Como es sabido, las extensas y detalladas bases de datos que genera el sistema People Meter tienen, tienen como destino principal a los canales de televisión, las agencias de publicidad y los avisadores, quienes desembolsan elevadas sumas de dinero por ellas. El interés de estos 
tres agentes por contar con dicha información se explica por razones obvias. Debido al régimen televisivo basado en el autofinanciamiento que rige en nuestro país, y a la consiguiente competencia por acaparar televidentes, la información sobre el comportamiento de las audiencias es vital para las organizaciones televisivas, las cuales tienen como principal fuente de ingreso a la inversión publicitaria. Esto ha llevado a que, tal como grafican dos investigadores estadounidenses refiriéndose al caso de su país, se dé la paradoja de que los canales elaboren un producto -contenidos-, con el objetivo de vender otro distinto -audiencias(Webster y Phalen, 1997: 43 y ss). Por otra parte, es un hecho que "los anunciantes invierten en los medios para aumentar sus ventajas y les interesa que esta inversión sea lo más rentable posible, es decir, que su mensaje llegue al mayor número de personas..." (Jauset, 2000: 27). Así, un conocimiento más acabado del comportamiento televisivo les permite a éstos -y a las agencias que los representan- determinar en qué canales, franjas horarias y programas les conviene contratar espacios de publicidad.

Dado este escenario, se puede concluir que los datos sobre el comportamiento televisivo generados por el sistema People Meter en Chile son observados con mucha atención, pero casi exclusivamente desde una perspectiva económico-aplicada. En este sentido, se han desarrollado sólo contados esfuerzos -algunos de los cuales aparecen citados en las referencias- por abordar las mencionadas bases de datos con fines propiamente teóricos. Ello se explica, en parte, por el carácter privado de la información que entrega el sistema People Meter. Sin embargo, esta omisión no deja de ser llamativa, puesto que en muy pocas áreas de la vida cotidiana es posible contar con datos comportamentales tan específicos y continuos en el tiempo como ocurre con los referentes al consumo televisivo.

Frente a esta situación, el presente estudio tuvo el propósito de aplicar observaciones sociológicamente relevantes sobre los datos disponibles sobre el comportamiento de los telespectadores en Chile, que fueron registrados según el procedimiento antes mencionado. Para ello se propuso, en primer lugar, distinguir la estructura de la exposición televisiva temporal y horaria que se desarrolló en Chile en el año 2001, tanto para el conjunto de la población como para segmentos específicos de ella. La identificación de dicha estructura debe ser tomada como un paso necesario orientado a entender cómo se comportan los televidentes chilenos.

La relevancia de los resultados a los que llegó este estudio eminentemente empírico, consistió, antes que nada, en incrementar el conocimiento existente sobre el comportamiento de los chilenos frente a un medio tan central como lo es la televisión. Dado que, a diferencia de lo que sucede en otros países, en Chile no se han realizado con anterioridad investigaciones del tipo propuesto, este trabajo puede calificarse como pionero en su ámbito. El esfuerzo se enmarca, asimismo, dentro de una preocupación esencial de la disciplina sociológica: describir y explicar el comportamiento agregado.

\subsection{La televisión y la investigación social teórica y práctica}

Denis McQuail inició su ya clásico libro “Introducción a la teoría de la comunicación de masas", afirmando que los medios de comunicación "revisten una importancia considerable -y todavía en aumento- en las sociedades modernas" (2000: 27). El presente estudio parte de una observación similar, pero tiene la particularidad de situar a la televisión en el lugar más destacado de todos. Para ello se apoya en la constatación de que en Chile este medio de comunicación es el más extendido, junto con ser el más creíble, informativo, educativo y entretenido a juicio de las personas (1). Al mismo tiempo, reconoce las importantes funciones que los individuos le atribuyen a la televisión. Una investigación de Javier Callejo, por citar solo 
un ejemplo, distinguió las siguientes representaciones sociales en torno a las funciones que cumpliría la televisión: dispositivo socializador, compañía, colaborador, fuente de consumo, ventana al mundo e instrumento de selección (1995: 92-101). Consideramos, en definitiva, que estudiar lo que podemos denominar como el fenómeno televisivo, implica adentrarse en uno de los fenómenos claves de nuestra sociedad contemporánea.

Desde la investigación social, ya sea en una perspectiva teórica -básica- o práctica -aplicada-, múltiples estudiosos se han aproximado a este medio de comunicación y su entorno. Si quisiéramos agrupar los aspectos que les han interesado a estos investigadores, podríamos enumerar tres campos: 1. los emisores del contenido televisivo, 2. el contenido televisivo en sí, y 3. los receptores de este contenido (2). Es posible reconocer que cada campo está vinculado a un aspecto de la clásica distinción comunicativa entre emisor, contenido/mensaje y receptor.

La aproximación al campo de los emisores se ha efectuado con el objetivo de conocer cómo opera la televisión en tanto sistema organizacional, es decir, de qué forma operan los procesos se encuentran detrás de lo que aparece finalmente en la pantalla. Un ejemplo clásico de este enfoque es el trabajo del sociólogo Herbert Gans (1980), quien estudió, por medio de la observación participante, cómo se trabajaba en las organizaciones televisivas CBS Evening News y NBC Nightly News. En una perspectiva aplicada, por otra parte, podemos contar los trabajos de asesoría organizacional que diversas empresas consultoras realizan hoy por hoy a pedido de determinadas organizaciones televisivas, que persiguen racionalizar su esquema de trabajo.

El segundo campo, en tanto, tiene como técnica de investigación por excelencia al análisis de contenido. Lo que interesa saber aquí no es tanto cómo llegó a emitirse determinado mensaje, sino qué tipos de contenidos se están haciendo públicos a través de la televisión. En Chile, por ejemplo, el Consejo Nacional de Televisión (CNTV) cuantifica periódicamente el tiempo otorgado a cada género de programa, y de este modo categoriza y sistematiza los contenidos presentados por la televisión abierta. Asimismo, muchas organizaciones televisivas realizan análisis de contenido internos con el fin de establecer comparaciones entre sus emisiones y las de su competencia. En un terreno más teórico, podemos contar a todos los trabajos que tienen como fin distinguir qué "imagen del mundo" se presenta en la televisión, así como las aproximaciones semiológicas realizadas a este medio (véase, por ejemplo, la aproximación a las series animadas realizada por Víctor Fanjzylber, 1997).

Finalmente, encontramos a las investigaciones que tienen como foco propiamente tal a las audiencias de televisión. A grandes rasgos, podemos encontrar tres enfoques privilegiados que se sitúan al interior de esta perspectiva de análisis. El primero dice relación con el estudio de los efectos que la televisión tendría sobre sus receptores. Éste ha sido probablemente uno de los mayores focos de interés en los estudios teóricos de los medios de masas (Webster y Phalen, 1997: 116). A lo largo de la historia de estas teorías, se ha considerado desde que los medios poseen desde el carácter de "todopoderosos", hasta que su influencia sobre los receptores se desarrolla de forma "negociada" (véase, para mayor profundización, McQuail, 2000: 493-528). En una orientación de tipo aplicada, por otra parte, se sitúan los estudios que intentan determinar cómo determinados mensajes (por ejemplo, un comercial) influyen en la conducta de quienes lo presenciaron.

El segundo punto principal en el campo de los receptores, corresponde al estudio de las percepciones o apreciaciones de los éstos frente a los mensajes televisivos. A través de encuestas, entrevistas, focus gruop u otras técnicas de investigación social, se busca registrar las valoraciones hacia la televisión en general, o contenidos en particular, reconocidas por 
grupos de interés. Un ejemplo de lo anterior lo constituye el ya mencionado estudio teórico de Javier Callejo. Las pesquisas que buscan determinar si determinado contenido televisivo fue del agrado de su audiencia y por qué, forman parte de la orientación práctica de esta perspectiva.

El análisis del comportamiento frente a la televisión es un tercera dimensión del análisis de las audiencias televisivas. Algunas de las interrogantes básicas que buscan ser contestadas desde esta perspectiva son: ¿qué patrones y hábitos de consumo televisivo desarrollan las audiencias de televisión? y ¿como influyen determinados variables temporales o de contenido en los índices de audiencia? Contestar a preguntas como las señaladas ha sido asumido, por cierto, tanto desde una perspectiva práctica (por ejemplo, los estudios aplicados que generan información para los encargados de programación de las organizaciones televisivas), como teórica (por ejemplo, los trabajos de James Webster, et. al, que se citan en las referencias). A nuestro juicio, este tipo de enfoque ha sido tratado en menor cuantía, comparativamente hablando, por los estudiosos de las audiencias de televisión. Dado que estamos concientes de la importancia de incrementar el conocimiento referido al comportamiento de las audiencias de televisión -más allá de los efectos de ésta pueda causar en aquéllas y de las apreciaciones que los receptores puedan manifestar frente a lo que ven-, el presente estudio ha asumido el desafío de abordar la última de las vertientes de estudio del fenómeno televisivo aquí descritas.

Cassetti y Di Chio (1999: 19-43) han desarrollado un esquema en el que exponen las áreas que consideran las más importantes del estudio televisivo que se aplica actualmente. Cada ámbito ha sido clasificado según su objeto de análisis, los instrumentos que utiliza, la operación metodológica prevaleciente, las disciplinas involucradas y las diversas modalidades que asume (Cuadro 1.1). Como puede apreciarse, el enfoque utilizado en este trabajo corresponde al primero de los 11 ámbitos enumerados por ambos investigadores italianos. Las áreas 2, 3, 4 y 6 , en tanto, apuntan claramente a lo que llamamos enfoques de percepción y apreciación de las audiencias. 


\section{Cuadro 1.1: Principales Ámbitos del Análisis Televisivo Según Cassetti y Di Chio} (1999: 19-43)

\begin{tabular}{|c|c|c|c|c|c|}
\hline AREA & OBJETO & INSTRUMENTOS & OPERACION & DISCIPLINAS & MODALIDADES \\
\hline $\begin{array}{l}\text { 1. Medición de } \\
\text { audiencia }\end{array}$ & $\begin{array}{l}\text { Cantidad y } \\
\text { composición del } \\
\text { público }\end{array}$ & $\begin{array}{l}\text { Audímetro, diarios } \\
\text { de consumo, } \\
\text { indicadores y } \\
\text { escáner }\end{array}$ & Registrar & Sociología, estadística & $\begin{array}{l}\text { Investigaciones } \\
\text { mediante audímetro }\end{array}$ \\
\hline $\begin{array}{l}\text { 2. Estudio de } \\
\text { actitudes }\end{array}$ & $\begin{array}{l}\text { Percepciones, } \\
\text { reacciones, } \\
\text { valoraciones } \\
\text { relativas a lo } \\
\text { que se ve en } \\
\text { TV }\end{array}$ & \begin{tabular}{|l|} 
Cuestionario, \\
escalas de \\
actitudes
\end{tabular} & Preguntar & $\begin{array}{l}\text { Sociología, estadística, } \\
\text { psicología }\end{array}$ & $\begin{array}{l}\text { Encuestas y sondeos, } \\
\text { investigaciones } \\
\text { psicosociales }\end{array}$ \\
\hline $\begin{array}{l}\text { 3. Medición de } \\
\text { apreciación }\end{array}$ & $\begin{array}{l}\text { Apreciación de } \\
\text { un programa }\end{array}$ & \begin{tabular}{|l|} 
Cuestionario, \\
escalas de \\
valoración
\end{tabular} & Preguntar & Sociología, estadística & $\begin{array}{l}\text { Mediciones cuantitativas } \\
\text { de índice de aceptación }\end{array}$ \\
\hline $\begin{array}{l}\text { 4. Estudio de } \\
\text { motivaciones }\end{array}$ & $\begin{array}{l}\text { Necesidades, } \\
\text { vivencias, } \\
\text { razones } \\
\text { profundas del } \\
\text { consumo }\end{array}$ & $\begin{array}{l}\text { Entrevista clínica, } \\
\text { test proyectivos }\end{array}$ & $\begin{array}{l}\text { Preguntar, } \\
\text { relacionar }\end{array}$ & Psicología, psicoanálisis & $\begin{array}{ll}\text { Investigaciones } & \text { de } \\
\text { motivaciones, } & \\
\text { investigaciones } & \\
\text { creativas } & \end{array}$ \\
\hline $\begin{array}{l}\text { 5. Registro de } \\
\text { reacciones } \\
\text { inmediatas }\end{array}$ & $\begin{array}{l}\text { Reacciones } \\
\text { espontáneas } \\
\text { ante lo que se } \\
\text { ve en TV }\end{array}$ & $\begin{array}{|lr|}\text { Indicador } & \text { de } \\
\text { reacción inmediata }\end{array}$ & Registrar & Psicología, estadística & $\begin{array}{lr}\text { Test de } & \text { reacción } \\
\text { inmediata } & \text { (CCPI, } \\
\text { MPM...) } & \\
\end{array}$ \\
\hline $\begin{array}{l}\text { 6. Análisis } \\
\text { multivariado }\end{array}$ & $\begin{array}{l}\text { Percepción y } \\
\text { valoración de } \\
\text { los } \\
\text { espectadores }\end{array}$ & \begin{tabular}{|l|} 
Técnicas \\
estadísticas \\
multivariadas
\end{tabular} & Relacionar & $\begin{array}{l}\text { Marketing, } \\
\text { psicometría }\end{array}$ & $\begin{array}{lr}\text { Mapping perceptivo, } \\
\text { segmentación del } \\
\text { mercado }\end{array}$ \\
\hline $\begin{array}{l}\text { Investigacione } \\
\text { s sobre estilos } \\
\text { de vida }\end{array}$ & $\begin{array}{l}\text { Variables } \\
\text { socioculturales, } \\
\text { de valores, } \\
\text { psicológicas }\end{array}$ & $\begin{array}{l}\text { Cuestionario, } \\
\text { técnicas } \\
\text { estadísticas } \\
\text { multivariadas }\end{array}$ & $\begin{array}{l}\text { Preguntar, } \\
\text { relacionar }\end{array}$ & $\begin{array}{l}\text { Sociología, psicología, } \\
\text { estadística, marketing }\end{array}$ & Psicografías \\
\hline $\begin{array}{l}\text { 8. Etnografías } \\
\text { del consumo }\end{array}$ & $\begin{array}{l}\text { Modalidades, } \\
\text { formas, tipos de } \\
\text { consumo }\end{array}$ & $\begin{array}{l}\text { Observación } \\
\text { participante, } \\
\text { conversación, } \\
\text { entrevista en } \\
\text { profundidad }\end{array}$ & Observar & $\begin{array}{l}\text { Micro-sociología, } \\
\text { etnografía, psicología }\end{array}$ & $\begin{array}{lr}\text { Etnografías } & \text { del } \\
\text { consumo, } & \text { historias } \\
\text { vitales } & \\
\end{array}$ \\
\hline $\begin{array}{l}\text { 9. Análisis de } \\
\text { contenido }\end{array}$ & $\begin{array}{l}\text { Contenidos } \\
\text { transmitidos por } \\
\text { la TV }\end{array}$ & $\begin{array}{ll}\text { Fichas } & \text { de } \\
\text { identificación, } \\
\text { paquetes } \\
\text { informáticos }\end{array}$ & $\begin{array}{l}\text { Realizar un } \\
\text { inventario }\end{array}$ & $\begin{array}{l}\text { Sociología, estadística, } \\
\text { lingüística informática }\end{array}$ & Análisis de contenido \\
\hline $\begin{array}{l}\text { 10. Análisis de } \\
\text { textos } \\
\text { televisivos }\end{array}$ & $\begin{array}{l}\text { Aspectos } \\
\text { lingüísticos, } \\
\text { estrategias } \\
\text { textuales de los } \\
\text { programas } \\
\end{array}$ & $\begin{array}{l}\text { Fichas de } \\
\text { identificación, } \\
\text { parrillas de lectura, } \\
\text { categorías de análisis }\end{array}$ & $\begin{array}{l}\text { Componer } \mathrm{y} \\
\text { descomponer }\end{array}$ & $\begin{array}{l}\text { Lingüística, semiótica, } \\
\text { narratología, iconografía }\end{array}$ & Análisis textuales \\
\hline $\begin{array}{l}11 . \quad \text { Estudios } \\
\text { culturales }\end{array}$ & $\begin{array}{l}\text { Relación entre } \\
\text { TV y sociedad: } \\
\text { formas culturales, } \\
\text { funciones } \\
\text { ideológicas }\end{array}$ & $\begin{array}{l}\text { Categorías de } \\
\text { análisis, paradigmas } \\
\text { interpretativos }\end{array}$ & Relacionar & 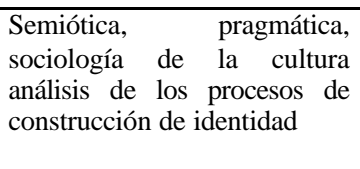 & $\begin{array}{l}\text { Análisis de las funciones } \\
\text { sociales de los medios, } \\
\text { análisis de la ideología }\end{array}$ \\
\hline
\end{tabular}

\subsection{Las audiencias de televisión como masas y su medición cuantitativa}

Cuando se estudian los comportamientos de las audiencias de televisión, se están estudiando los comportamientos de grandes masas de personas. Para nuestros fines, entenderemos una masa como una "colección heterogénea de individuos que están separados entre sí y actúan de forma autónoma", pero que, sin embargo, "están unidos por un objeto común de atención" (Webster y Phalen, 1997: 7). En términos de audiencia televisiva, se ha establecido que el objeto común de atención es el contenido televisivo al cual éstos se encuentran expuestos. De este modo, la audiencia televisiva se definirá por la exposición a dicho medio (3). Esto se encuentra íntimamente ligado a la opción metodológica prevaleciente -enormemente beneficiada por sistemas electrónicos como el People Meter-, que consiste en aproximarse 
cuantitativamente al comportamiento televisivo. Tal como señala Amparo Huertas, "la medición de audiencia en televisión se ha definido tradicionalmente como un estudio cuyo objetivo principal es conocer el número de personas que consumen productos televisados, es decir, a la hora de acotar el concepto de medición, ha prevalecido su carácter cuantitativo" (1998: 17).

Debe señalarse que el hecho de dirigir exclusivamente la atención a los comportamientos manifiestos de consumo televisivo, esto es, "el 'quién' ve 'qué', 'cuándo' y 'durante cuánto tiempo'” (Cassetti y Di Chio 1999:34), no ha estado ajeno a las críticas. La propia Amparo Huertas enfatiza en la necesidad de incorporar enfoques cualitativos que registren las percepciones subjetivas de los individuos a la hora de estudiar las audiencias. Es así como sugiere incluir en las mediciones de comportamientos preguntas referidas a la apreciación, tales como: ¿por qué ve televisión?, ¿cómo la ve? y ¿qué opinión le merece lo que ve? (1998: 169 y ss.). Otros autores, por ejemplo lan Ang (1996), rechazan de plano centrarse en análisis matemático de las audiencias, ya que de este modo se perderían de vista las particularidades del consumo televisivo individual.

Lo anterior se relaciona, por cierto, con el hecho de que los actuales sistemas de medición electrónica no son capaces de registrar actitudes, motivaciones u opiniones de los televidentes. Con ello, es imposible saber, por ejemplo, si las personas están disfrutando o no el programa que están viendo, elementos que igualmente forman parte de la complejidad del consumo televisivo. Seguramente en un futuro no muy lejano, aspectos del tipo mencionado se incorporarán a los registros sistemáticos de la medición de audiencias. Hoy por hoy, la información que nos entrega la observación electrónica, se centra en los actos de encendido o apagado el televisor y de cambio de canal en tiempos determinados.

Cabe destacar que el audímetro no es la única forma mediante la cual se pueden obtener datos numéricos correspondientes a las características y la magnitud de la masa de televidentes. En efecto, "a lo largo de la historia de la medición de la audiencia en televisión se han aplicado tres métodos de recogida de datos: las encuestas por entrevista, el panel con diario de escucha [o cuadernillo recordatorio] y el panel audiométrico" (1) (Huertas 1998: 77).

Habiéndose realizado experiencias previas para la radio, "la audiometría aplicada a la televisión se inició en EE.UU. en los años cincuenta". (Jauset, 2000: 166). Junto con los cambios tecnológicos que ha experimentado el proceso de medición de audiencias, también se han desarrollado modificaciones en la periodicidad de la recogida de información y en el tipo de muestra utilizada para la misma. Hoy en día impera el registro sin interrupciones y aplicado a grandes muestras de tipo panel.

La medición cuantitativa de audiencias, por otra parte, se rige por los mismos patrones de todo sondeo, es decir, intenta extrapolar para todo el universo de estudio los resultados obtenidos en un grupo representativo. Estadísticamente hablando, esto implica contar con un margen de error variable, pero nunca igual a cero. Por ello, todos los analistas de audiencias recalcan que "no hay que olvidar que el sondeo, en general y por naturaleza, es sólo una estimación, aunque a partir de sus resultados, gerentes, directivos y políticos tomen importantes decisiones de gran trascendencia para el desarrollo y el futuro del país" (Jauset, 2000: 31). Quizás esta afirmación suene algo exagerada, pero lo que sí es cierto para el tema que nos ocupa, es que los índices de audiencias provenientes de un acotado grupo de hogares son tomados, en ocasiones, como datos reales o, al menos, como totalmente representativos del universo de estudio.

Con todo, existe consenso al señalar que el audímetro es el instrumento de medición de audiencias más exacto que se ha desarrollado hasta el momento. Es por ello que los 
investigadores le otorgan mayor confianza a sus resultados que a los obtenidos por medio de encuestas o diarios de consumo. Entre las múltiples ventajas del audímetro se cuentan el que reduce notablemente el error humano, que entrega una serie de informaciones de las que no se puede disponer de otro modo (por ejemplo, la evolución del consumo durante breves o muy prolongadas unidades temporales) y que permite disponer de una fuente de datos sistemática durante 24 horas diarias a lo largo de todo el año (Cassetti y Di Chio 1999: 54).

\subsection{El funcionamiento del sistema People Meter en Chile}

Resulta necesario referirse brevemente a las principales características del sistema de medición de audiencias People Meter que rige hoy en Chile, puesto que este mecanismo determinó directamente el tipo y la calidad de los datos que fueron analizados en el presente estudio.

En 1991, Time-lbope se adjudicó la licitación del primer sistema de medición electrónica de audiencias de televisión de nuestro país, la cual había sido convocada por las asociaciones de televisión, publicidad y avisadores. A partir del año siguiente, esta empresa comenzó a entregar periódicamente los resultados de sus mediciones. El nuevo sistema, que había sido estandarizado "conforme a la norma mundial para todos los procedimientos de la investigación de audiencias" (Time-lbope, 1998: 2), fue bautizado como People Meter.

Dicho sistema, que hasta el día de hoy no ha experimentado mayores modificaciones, está basado en un pequeño aparato -o audímetro-, que se instala en el receptor de un televisor con el fin de que registre continuamente si éste se encuentra encendido o apagado, y qué señal está sintonizada, junto con las características sociodemográficas básicas de las personas que están viendo televisión. Opera a partir de una muestra de tipo panel, es decir, estable en el tiempo. Toda la información recabada es transmitida instantáneamente, vía enlaces radiales, a la central de Time- Ibope y posteriormente despachada a los agentes contratantes.

La elección de los hogares estudiados comenzó con la selección probabilística de una gran muestra maestra, proveniente del sector geográfico Gran Santiago. Posteriormente, se extrajeron de ella, de forma aleatoria, cuatro grupos de hogares estratificados según nivel socioeconómico (se excluye el segmento E). Cada grupo abarcó una cantidad equivalente de hogares, la cual fue de 75 durante los primeros años del estudio y hoy se sitúa entre las 110 y 115 viviendas. En consecuencia, la muestra panel pasó de incluir a 300 a incluir a 450 hogares en el transcurso de los nueve años que lleva funcionando el estudio. A nivel individual, en tanto, se contabilizan actualmente un poco más de 1800 personas (se excluyen los menores de cuatro años) (5). Al momento de confeccionar los índices de audiencia, los datos -representativos sólo de la capital- son ponderados sobre la base del peso que el censo nacional actualizado de 1992 le otorga a cada segmento sociodemográfico. En cuanto a la rotación del panel, ésta tiene un promedio de 12 meses, con un máximo de 14.

Aun cuando se reconoce que los datos del sistema People Meter son los más exactos que dispone actualmente la industria televisiva, este mecanismo -al igual que otros sistemas similares en el mundo- no deja de recibir diversas críticas. Entre éstas se cuentan el tamaño de su muestra, el hecho de que siga estando propenso al error humano (motivado por el olvido o el engaño al momento de registrar el inicio y el término de la exposición televisiva individual) y el que, en teoría, modifique los comportamientos usuales de los televidentes estudiados. Debe destacarse que existen, asimismo, opiniones que minimizan todas estas objeciones. Por ejemplo, respecto de la primera, Cristóbal Paúl señala que "el tamaño de la muestra que se utiliza en Chile no es menor, proporcionalmente, [la de] otros países, como Estados Unidos o Argentina" (1998: 10). Asimismo, Pablo Marshall sostiene que la validez de los datos se 
incrementa en la medida en que se analicen franjas temporales mayores a los 60 segundos, por ejemplo, promediando una serie de minutos sucesivos6). Por otra parte, estudios privados orientados a evaluar el funcionamiento en terreno del sistema People Meter, han concluido que las personas, en su gran mayoría, suelen utilizar correctamente el audímetro y no varían su consumo televisivo habitual.

Es interesente percatarse, sin embargo, que, a pesar de todas las críticas que desde el punto de vista de la validez, fiabilidad y representatividad de los datos puedan realizarse al sistema People Meter, su influencia de facto al momento de tomar decisiones programáticas y de inversión publicitaria es extremadamente importante. Es sabido que una leve diferencia en puntos de rating -incluyendo aquellas que desde una perspectiva estadística se encuentran dentro del margen de error- puede desencadenar decisiones económicas de grandes proporciones. A juicio de Emili Prado, “... puede resultar paradójico que unas medidas tan imprecisas orienten decisiones económicas de magnitudes escalofriantes, como son las referentes a la inversión publicitaria en el ámbito planetario..." (en Huertas, 1998: 12) (7).

\subsection{Las variables dependientes en el estudio de audiencias}

Los índices de audiencias son cifras numéricas que representan tamaños y composiciones de la masa de individuos que se han expuesto a la pantalla de televisión. La utilidad básica de estas cifras consiste en que permiten a la industria televisiva estimar el total de la audiencia que presenció determinados programas o franjas horarias. Como se ha señalado, gracias al advenimiento de la medición electrónica del comportamiento televisivo, estos índices cada vez son más exactos y fáciles de procesar.

Cuando se habla de audiencias de televisión, tanto a nivel de hogares como de individuos (8), se suele pensar exclusivamente en el rating, a pesar de que éste es sólo uno de los múltiples índices de audiencias existentes (ver Cuadro 1.2). El rating -o audiencia media- corresponde "al porcentaje de individuos u hogares que sintonizan un canal en un minuto determinado" (TimeIbope, 1998: 46). En otras palabras, expresa la proporción de la audiencia que se expone a la televisión en un determinado momento del tiempo, en relación al total. Este índice, al igual que todos los demás, puede aplicarse tanto a programas como a franjas horarias, simplemente promediando los minutos incluidos en dichos espacios. El rating puede ser medido tanto para el total de la población como para grupos específicos de ésta.

Otros índices de audiencias importantes son el share -o cuota de pantalla- y el reach -o alcance-. El primero "corresponde a la sintonía de un determinado canal respecto de los hogares [o individuos] viendo TV", es decir, del total de televisores encendidos (Time-lbope, 1998: 50). El reach, en tanto, equivale al "porcentaje de telespectadores (unidades que han tenido contacto con un evento) sobre el total de la población" (Time lbope, 1998: 51). La particularidad de este último índice es que considera a cada hogar o individuo que se expone más de una vez a la televisión como si hubiera tenido un sólo contacto. Se trata, por lo tanto, de un índice de audiencias no duplicadas. 


\section{Cuadro 1.2: Índices Mayormente Utilizados en la Investigación de Audiencias (Jauset,} 2000: 234)

- Audiencia media (rating)

- Cuota de pantalla (share)

- Audiencia acumulada (reach)

- Audiencia máxima

- Audiencia mínima

- Audiencia total (TTV)

- Home Using Televisión (HUT)
- People Using Television (PUT)

- Índice de fidelidad o permanencia

- Índice de afinidad

- Índice de aportación a la cadena

- Índice de superioridad jerárquica (ISJ)

- Índice de aprovechamiento genérico $(I A G)$

- Índice aportación TV

\subsection{Las variables independientes en el estudio de audiencias}

Toda medición de audiencias tiene como finalidad determinar la extensión del conjunto de masas de telespectadores. Al mismo tiempo, "todos ellos son clasificados a partir de diferentes variables, como por ejemplo el sexo o la clase social, lo que da cuenta de su naturaleza o composición" (Huertas, 1998:18). Estas categorías de clasificación de telespectadores constituyen las variables independientes que permitieron establecer diferencias en los índices de audiencias que fueron tomados por este estudio como variables dependientes. ¿Qué posibilidades de clasificación nos entrega el sistema People Meter? La información que da a conocer Time-lbope incluye la discriminación sobre la base de todas las variables que se señalan en el Cuadro 1.3. Puede constatarse que se excluyen diversas variables que, sin duda, serían de gran interés teórico al momento de comparar el consumo televisivo, como, por ejemplo, el tipo de trabajo realizado, el número de hijos o personas viviendo en el hogar y la posición política o valórica, entre otros. No obstante, este estudio parte de la base de que las variables sociodemográficas, temporales, horarias y de contenido son suficientes para dar cuenta de la estructura general del consumo televisivo que se desarrolla en Chile.

Adicionalmente, es posible enfrentar la base de datos del sistema People Meter construyendo grupos comportamentales especiales. Esto, gracias al software Telereport. Mediante dicho programa, un investigador está en condiciones de generar targets específicos (por ejemplo, poseedores de televisión por cable (9), consumidores fuertes de televisión -heavy users- o televidentes leales a determinado programa o canal, entre muchos otros) y observar cómo se comporta este grupo creado en diferentes circunstancias. Asimismo, sólo gracias a este programa es posible observar los efectos de herencia, repetición y fidelidad, fenómenos de alto interés en el marco del estudio del comportamiento de las audiencias televisivas. 
Cuadro 1.3: Resumen de Variables Independientes que Incorpora el Sistema People Meter

\begin{tabular}{|c|c|c|}
\hline VARIABLE & VALORES & $\begin{array}{c}\text { TIPO DE } \\
\text { VARIABLE }\end{array}$ \\
\hline $\begin{array}{c}\text { Sexo } \\
\text { GSE }\end{array}$ & $\begin{array}{c}\text { Hombres y mujeres } \\
\text { Categorías desde "4-10 años" hasta "60 y más } \\
\text { años" } \\
\text { ABC1, C2, C3 y D }\end{array}$ & Sociodemográfica \\
\hline $\begin{array}{c}\text { Fecha } \\
\text { Días de la semana }\end{array}$ & $\begin{array}{c}\text { Semana, mes y año } \\
\text { Lunes a domingo }\end{array}$ & Temporal \\
\hline Horario & Por minutos desde las 6 AM las 24 horas del día & Horaria \\
\hline $\begin{array}{c}\text { Canal } \\
\text { Programa } \\
\text { Género de programa }\end{array}$ & $\begin{array}{c}\text { Todos los canales de televisión abierta y por cable } \\
\text { Todos los programas de la televisión abierta } \\
\text { Periodísticos, ficción, diversión/entretenimiento, } \\
\text { deportivos, cultura/educación, infantil, juvenil y } \\
\text { otros }\end{array}$ & De contenido \\
\hline
\end{tabular}

1.7. El modelo estructural de Webster y Lichty y los patrones del comportamiento televisivo

Quienes se han dedicado al estudio teórico del comportamiento de las audiencias de televisión, han recurrido de forma reiterada a la idea de los patrones o hábitos de consumo. Esto dice relación con el hecho de que, tal como dice Jauset, "es menos difícil prever el comportamiento de las masas que el comportamiento individual" (2000: 202). En otras palabras, si nos aproximamos a masas de personas, los comportamientos que a nivel individual son altamente variables, tienden a regularizarse. Es por ello que muchos autores han estado en condiciones de formular "leyes" que permitirían predecir los valores de índices de audiencias bajo determinadas condiciones.

En su esfuerzo por entender los patrones de la exposición televisiva, James Webster y Lawrence Lichty desarrollaron un modelo que busca dar cuenta del comportamiento de las audiencias del conjunto de los medios de comunicación. Partieron de la premisa de que "el comportamiento de las audiencias puede ser localizado en la intersección entre los miembros de la audiencia y los medios de comunicación" (Webster y Phalen, 1997: 24). Así, diferenciaron los factores intervinientes según si éstos están asociados a la audiencia o al medio. Ambos tendrían una influencia sustancial sobre los patrones de la exposición televisiva. Para enfocar con mayor precisión los diferentes niveles de análisis, en cada categoría los autores hicieron una distinción ulterior entre determinantes estructurales e individuales. Los primeros equivalen a factores que son comunes a -o características de- la masa. Los factores individuales, en tanto, son determinantes que se inscriben en una persona u hogar (ver Cuadro 1.4). 


\section{Cuadro 1.4: Modelo de comportamiento de audiencias de We bster y Lichty (2000: 181)}

\begin{tabular}{|c|}
\hline Factores de audiencia \\
Estructurales \\
1. Audiencia potencial \\
2. Audiencia disponible \\
Individuales \\
1.Necesidades/Gustos/ \\
Preferencias \\
2. Conocimiento de las \\
opciones de \\
programación \\
3. Solidaridad de grupo \\
\hline
\end{tabular}

\begin{tabular}{|c|}
\hline Exposición \\
Un momento del tiempo \\
1. Rating \\
2. Cuota de pantalla \\
3. Circulación \\
Acumulados \\
1. Rating acumulado \\
2. Cobertura y \\
frecuencia \\
3. Duplicación \\
4. Fidelidad \\
\hline
\end{tabular}

\begin{tabular}{|c|}
\hline Factores de medios \\
Estructurales \\
1. Cobertura medial \\
2. Opciones de \\
contenido en el canal y \\
su competencia \\
Individuales \\
1. Número de \\
televisores en el hogar \\
2. Suscripciones \\
3. Tecnologías poseídas \\
\hline
\end{tabular}

Estos autores plantean, en definitiva, que para predecir los índices de audiencia de un programa o una franja horaria -tanto para uno o más momentos en el tiempo- deben sopesarse los elementos indicados en el Cuadro 1.4. Ahora bien, quizás el mayor aporte de Webster y Lichty ha sido su constatación empírica referente al mayor peso de los factores estructurales en la determinación de los índices de audiencias. Así, señalan: "para entender el comportamiento de masas de televidentes, abogamos por considerar primero las explicaciones estructurales", puesto que, "estadísticamente hablando, no es inusual encontrar que tres o cuatro factores estructurales expliquen importantes porciones de la varianza en el comportamiento de masas de televidentes". (Webster y Phalen, 1997: 46). De este modo, los autores nos invitan a asumir la noción contra-intuitiva de que las preferencias subjetivas de los televidentes poseen una importancia marginal al momento de determinar la exposición televisiva agregada.

Debe reconocerse que el modelo de Webster y Phalen no es aplicable a un mercado televisivo como el nuestro, el cual, debido a que solo registra mediciones en un sector geográfico, mantiene invariantes los factores estructurales asociados tanto a los espectadores como a los medios. Al mismo tiempo, el caso chileno tiene la complicación adicional de que los factores mediales individuales no son dados a conocer a través del sistema People Meter. Es por ello que la aproximación al fenómeno de los patrones y rutinas en el consumo televisivo debe replantearse en un escenario como éste. En concreto, apostamos a que el consumo televisivo estructural es posible de ser observado explorando la relación entre las variables temporales y horarias, y el porcentaje total de televisores encendidos. De este modo, es posible determinar si existe $o$ no alguna forma de independencia entre el rating total y la variable oferta de contenidos.

Diversos investigadores han trabajado sobre este mismo ámbito. Gensch y Shaman, por ejemplo, llegaron a al conclusión de que el número de televisores encendidos dependía más del día, la hora y la estación del año que del contenido del programa en sí (Jauset, 2000: 214). En esta misma línea, Blum y Lindheim detectaron una estrecha relación entre el éxito de un programa y su ubicación horaria (Huertas, 1998: 23). En las últimas secciones del siguiente apartado, veremos cómo se aplica este tipo de fenómeno para el caso chileno. 


\section{La estructura del consumo televisivo en Chile durante el año 2001}

\subsection{Introducción}

En este apartado se persigue describir la estructura general del comportamiento de las audiencias de televisión en Chile. Para ello se dará cuenta de las características fundamentales de la exposición televisiva registrada por el sistema People Meter durante el año 2001 y se distinguirán los principales cambios producidos sobre la base de variables temporales y de franjas horarias. No nos detendremos aquí en el consumo televisivo por canal o programa específico, puesto que lo que interesa es conocer con mayor detalle cómo se desarrolla la exposición de los chilenos a la televisión, independiente de la oferta de contenidos. El análisis se hará extensivo tanto para el total de la población como para diversos segmentos sociodemográficos de ella (10).

En términos prácticos, este estudio comenzó con la generación de 13 bases de datos que resumían el rating promedio, agrupado en períodos de 15 minutos, que marcó durante los 365 días del año 2001cada uno de los grupos sociodemográficos analizados. Esto dio un total de 35.040 cifras de rating para cada grupo. El procesamiento de toda esta información, proporcionada por el Centro de Estudios Mediática de la Universidad del Desarrollo, se llevó a cabo mediante los software SPSS y Excel.

La bibliografía extranjera especializada (ver referencias) menciona una serie de hipótesis sobre el consumo televisivo que han sido verificadas por estudios empíricos realizados en otros países. Contrastar estas afirmaciones para el caso chileno fue de gran utilidad teórica al momento de distinguir la estructura del comportamiento televisivo que se lleva a cabo en nuestro país. Entre dichas nociones destacan las siguientes:

- Las mujeres consumen mayor cantidad de televisión que los hombres.

- Los jóvenes ven menos televisión que los individuos mayores.

- A menor nivel socioeconómico se desarrolla un mayor consumo televisivo.

- En los períodos de vacaciones, aumenta el consumo televisivo.

- En los meses de invierno se consume más televisión que en los de verano.

- Los fines de semana se consume menos televisión que durante el resto de la semana.

- Los horarios de mayor consumo televisivo son la sobremesa y el prime time.

En las dos secciones finales de esta sección, se explorará la importancia que le cabe a las variables temporales estación del año, mes y día de la semana en las variaciones del rating individual total. Con este fin, observaremos la distribución anual de los promedios más altos y bajos en las franjas de mayor consumo televisivo del día, y el porcentaje de desviación que registran estas mismas cifras a lo largo del año.

\subsection{El Rating total}

Según los datos generados por el sistema People Meter, el rating total del año 2001 -a nivel individual- marcó una media diaria de 13,29 puntos. Como ya se señaló en el apartado anterior, el rating individual se define como el porcentaje de personas que sintonizan la televisión en un minuto determinado. Así, el rating de un día corresponde a la media de telespectadores de todos sus minutos, y equivale a la suma de la audiencia de todos los canales, incluyendo la televisión por cable (11). A continuación revisaremos de qué forma fluctuó este índice a lo largo 
del año 2001 y veremos cómo se comportó respecto de variables temporales y de franjas horarias.

El Gráfico 21 muestra el rating total promedio, según la estación del año. Podemos observar que el consumo televisivo alcanza su mayor expresión en invierno con 14,50, mientras que en verano desciende a su punto mínimo: 11,53. En primavera, en tanto, se registró un rating total muy similar al del promedio anual. Las diferencias de rating entre las estaciones extremas se entiende mejor al momento de desagregar los datos según meses. En efecto, podemos constatar que el mes de julio fue el de mayor consumo televisivo (Gráfico 2.2), seguido de agosto y junio. Después y antes de julio, los ratings totales descienden -con la sola excepción del paso de septiembre a octubre-, alcanzando su valor más bajo del año en febrero (4,3 puntos menos). Los bajos ratings registrados en el período de vacaciones escolares llaman la atención porque contradicen algunas constataciones realizadas por estudios extranjeros. Cabe señalar que un posible factor que distorsiona estas cifras es el hecho de que sistema People Meter no mide el consumo televisivo realizado en localidades distintas al Gran Santiago.

En cuanto a los días de la semana, podemos constatar a partir de la información presentada en el Gráfico 2.3, que existe gran similitud en los índices anuales de audiencia de los cinco días hábiles. Sus ratings se encuentran entre los 13,64 (jueves) y los 13,94 puntos (miércoles). Respecto del fin de semana sí hay diferencias importantes, especialmente con el sábado, día en el que se registró un consumo televisivo de sólo 11,82 puntos. El domingo acumula un rating algo mayor, pero aún por bajo del resto de la semana. Cabe señalar, por último, que el promedio correspondiente al total de los días feriados del año 2001, da una cifra prácticamente equidistante de los días hábiles y del fin de semana: 12,94 puntos.

El Gráfico 2.4 presenta, sobre la base del promedio anual, la evolución del rating diario dividido en períodos de 15 minutos. En el eje $X$ del gráfico se indica el minuto de inicio de cada uno de estos subperíodos. Nótese que el sistema People Meter toma como comienzo de un día el registro de datos que efectúa a las 6:00 A.M. En la evolución del rating diario destacan dos marcadas cúspides de consumo televisivo: alrededor de las 15:00 hrs. y en torno a las 22:30 hrs. Tras el peack diario -ubicado en la franja denominada prime time comienza un pronunciado declive del porcentaje de televisores encendidos, el cual suele postergarse algo los días viernes y sábado, así como los meses de enero y febrero.

Basándonos en categorías utilizadas por Time-lbope, distinguimos 5 franjas del día (matinal, mediodía / sobremesa, vespertino, prime time y trasnoche), cuyos ratings promedio nos permitirán profundizar en las diferencias de consumo televisivo según fechas y grupos sociodemográficos. Cabe destacar que el mayor consumo televisivo del día de todas las fechas y en todos los grupos corresponde al prime time, franja que en sus 5 horas de duración suele acaparar en torno al 39\% del consumo diario. Los programas de mayor éxito de la televisión abierta -teleseries, noticieros y estelares- se emiten precisamente en tal período.

Si nos detenemos en los ratings promedio de las cinco franjas mencionadas, podemos detectar diversas particularidades que nos explican de mejor modo las diferencias respecto del consumo televisivo total que revisamos más arriba (ver Cuadro 2.1). Así, los índices de las estaciones del año se expresan privilegiadamente en las franjas vespertino y prime time. En las demás franjas los ratings no concuerdan con las tendencias generales antes descritas. Incluso, durante el trasnoche el mayor consumo se da verano.

En cuanto a los meses, destaca que el de mayor consumo televisivo -julio- se aleja de los demás en las franjas mediodía y la sobremesa y vespertino, pero que empata con agosto en el 
prime time y tiene sólo el cuarto mayor rating en el trasnoche. El mes de febrero, por su parte, está por debajo de todos los demás durante cuatro las franjas del día, destacando su bajo rating en la franja del prime time. La excepción la constituye el trasnoche, en el cual febrero pasa a ocupar el primer lugar en consumo televisivo.

Respecto de los días de la semana, por último, destaca que en la franja vespertino se da un notorio equilibrio entre todos los días de la semana, al punto de que es la única combinación entre rating y fecha del grupo total que no es significativa al $5 \%$. En el prime time, el rating promedio del viernes se encuentra cercano al del domingo, estando ambos por debajo de las cifras de lunes a jueves. Por otra parte, los días hábiles tienen un fuerte mayor consumo de televisión que los fines de semana en tres franjas: mediodía y sobremesa, vespertino y prime time. El análisis de los datos referentes al uso del tiempo en Chile realizado por el sociólogo Sebastián Ureta, permite sugerir que las diferencias en la franja de las 11:30 a las 16:00 hrs. se deben a que durante los fines de semana se incrementa el trabajo y los trámites hogareños (por ejemplo, el aseo y las compras). El menor consumo en el prime time, por su parte, estaría dado por la mayor dedicación a las actividades de sociabilidad, tal como lo son encuentro con amigos y familiares (12).

\subsection{El Rating diario según grupos sociodemográficos}

El Gráfico 2.5 detalla el rating anual promedio de cada uno de los trece grupos que se abordan en este estudio. A las categorías de las variables sexo, edad y nivel socioeconómico se agregó el grupo total (13)y el de las amas de casa sin trabajo (14). El mayor consumo televisivo está encabezado precisamente por este último grupo, con 19,34 puntos. Le siguen los adultos mayores $(17,29)$, las mujeres $(14,51)$ y el grupo $D(13,91)$. Por su parte, los adolescentes $(11,37)$, los niños $(11,64)$, los hombres $(11,96)$ y el grupo $A B C 1(12,10)$ son quienes promediaron el menor rating anual. Cabe destacar que el nivel socioeconómico muestra volúmenes de consumo televisivo menos dispersos que lo que sucede con el sexo y la edad. En los grupos etarios se da una relación de mayor rating a mayor edad, con la salvedad de que los adolescentes ven menos televisión en promedio que los niños.

En los Gráficos 2.6 y 2.7 se presenta información referente al rating diario de los hombres, las mujeres y las amas de casa. El Gráfico 2.6 muestra la evolución del rating según el promedio anual, mientras que el Gráfico 2.7 presenta el consumo televisivo realizado en las cinco franjas horarias del día. Las mujeres registran un mayor rating que los hombres desde las 7:00 hasta las 23:45 hrs. De este modo, los hombres sólo superan levemente a las mujeres en el horario de trasnoche. Las principales diferencias en consumo televisivo entre sexos se dan en torno al peack de las 15:00 hrs., el cual es muy marcado en las mujeres y prácticamente inexistente para los hombres.

La comparación entre el total de las mujeres y las amas de casa sin trabajo -suponiendo que éstas están integradas en su gran mayoría por personas de sexo femenino- permite vislumbrar de algún modo cómo incide el factor trabajo en el consumo televisivo. Podemos observar en el Gráfico 2.6 que las amas de casa siempre tienen un mayor rating que el total las mujeres, lo cual se acentúa entre las 14:00 y las 17:00 hrs. y también el en prime time (19:30-24:30). Si, junto con lo anterior, consideramos que las amas de casa registran también un mayor rating en la franja de trasnoche, tenemos que su mayor consumo televisivo excede con comodidad los límites horarios de la jornada laboral. Sin embargo, debido a que Time lbope no hace pública la variable trabajo de la muestra del sistema People Meter no nos es posible profundizar el análisis en torno a la relación entre este factor y la magnitud del consumo televisivo. 
En cuanto al rating según grupo etario, el Gráfico 2.8 muestra que entre las 13:30 y las 24:45 hrs. los adultos mayores (55 años o más) se distancian de forma significativa de los demás grupos. Posteriormente, comienza a descender rápidamente su porcentaje de televisores encendidos. Podemos constatar que el antes mencionado peack de las 15:00 hrs. tiene su origen precisamente en los adultos mayores. Su consumo en el prime time, señala niveles igualmente elevados, llegando a superar por algunos períodos los 40 puntos de rating. Por otra parte, vemos que los niños incrementan su rating más velozmente que ningún otro grupo desde las 9:00 y que registran el mayor consumo televisivo entre las 10:30 y las 13:00 hrs. Por último, destaca que los grupos menores de 30 años no muestran peacks muy importantes en el franja prime time, momento en el cual los adultos y los adultos mayores tienden a tomarles una gran distancia en el rating (Gráfico 2.9).

Es muy interesante el hecho de que las diferencias respecto del consumo diario que revisamos con relación a las variables sexo y edad, no se repliquen en los distintos niveles socioeconómicos (Gráfico 2.10). En efecto, el grupo D -que es el de mayor consumo y, por otra parte, el que tiene el mayor peso en el rating total con casi $40 \%$ - no registra una ventaja muy importante frente a los demás. Esta constatación es significativa, en la medida que, tal como se señaló en el apartado anterior, los canales de televisión suelen detenerse privilegiadamente en las cifras de rating según grupo socioeconómico -a nivel hogar-, ignorando muchas veces las variables sexo y edad. Destaca en el Gráfico 2.10 que durante gran parte del día se da la ecuación "mayor rating a menor nivel socioeconómico". En particular, esto se desarrolla entre las 12:00 y las 21:00 hrs. A partir de entonces, sube el consumo del grupo C2, con lo cual logra aventajar al C3 en el promedio diario. En la franja de trasnoche, en tanto, son los grupos ABC1 y C2 los que registran el mayor consumo televisivo, probablemente debido a su mayor porcentaje de posesión de televisión por cable (Gráfico 2.11).

El Cuadro 2.2 muestra un resumen del rating anual de todos los grupos sociodemográficos analizados, según consumo promedio diario, por fechas y franjas. Como puede verse, las diferencias más significativas a este respecto se encuentran en los grupos etarios.

\subsection{El Rating de grupos sociodemográficos según fechas}

Los Gráficos de 2.12 a 2.14 presentan el consumo televisivo dividido en las cuatro estaciones del año, según las variables sexo, edad y nivel socioeconómico. En cuanto a los hombres, el total de las mujeres y las amas de casa, podemos constatar que el rating se comporta aquí de forma equivalente a las tendencias anuales, vale decir, se registra el mayor consumo en las amas de casa y el menor en los hombres. Destaca, comparativamente hablando, el gran crecimiento en el consumo televisivo de las amas de casa en el paso de verano a otoño (de 15,57 a 20,83 puntos).

Respecto de los grupos de edad, resalta el que los adultos mayores no compartan la tendencia general de incrementar el consumo televisivo de otoño a invierno, disminuyéndolo incluso en 0,57 puntos de rating. Con esto, se transforman en el único grupo etario que no registra el mayor consumo televisivo del año en esta última estación. Algo similar ocurre con el segmento socioeconómico ABC1, el cual baja 0,77 puntos de otoño a invierno. Destaca en el Gráfico 2.14 que la tendencia anual en cuanto al consumo televisivo según nivel socioeconómico se mantiene inalterada en las cuatro estaciones, siendo el mayor rating promedio el del grupo $D$, seguido del C2, el C3 y el ABC1. Nuevamente, es posible detectar diferencias sólo de orden menor entre los distintos segmentos socioeconómicos -especialmente en las estaciones de verano, otoño y primavera-, en comparación con lo que sucede con las variables sexo y edad. 
El Cuadro 2.3 presenta toda la información referente al consumo elevisivo según grupos sociodemográficos y estaciones del año.

Las diferencias en el consumo mensual entre hombres y mujeres (Gráfico 2.15) no son significativas al $1 \%$. Vemos, consecuentemente, que ambos grupos registran prácticamente las mismas tendencias en el rating mensual promedio, siendo su mayor y menor diferencia en julio $(3,34)$ y enero $(1,35)$, respectivamente. Las amas de casa, en tanto, son el único grupo que rompe con la tendencia general al aumentar su rating de julio a agosto. A pesar de ello, mantiene una cómoda ventaja frente al total de las mujeres y los hombres en todos los meses del año.

Por otra parte, cinco grupos (amas de casa, adolescentes, adultos, adultos mayores y segmento D) se comportan distinto al total, al disminuir el rating de mayo a junio. También son cinco grupos los que disminuyen su rating de septiembre a octubre (hombres, niños, jóvenes, C2 y D), uno de los cuales -niños- muestra un crecimiento sostenido de febrero a julio, y luego una caída continuada hasta diciembre. Si se le suma el hecho de que los niños consumen menos televisión en enero que en diciembre, tenemos como resultado una tendencia "perfecta" en este grupo en el consumo de enero a diciembre. Por último, respecto de este ítem, destaca que en mayo y en diciembre el grupo C2 superó en consumo televisivo al D, y que en enero y febrero se dio la tendencia "mayor consumo a menor nivel socioeconómico" (ver Gráficos 2.16 y 2.17, y Cuadro 2.4).

En cuanto a las diferencias según día de la semana, destaca la pequeña variación en el consumo de los días lunes a viernes en todos los grupos analizados: la desviación estándar va desde 0,11 puntos de rating en el grupo C3 a 0,39 en las amas de casa. Por otra parte, es interesante constatar que los hombres son el único grupo que registra un consumo televisivo equivalente los fines de semana que los días hábiles, lo cual se debe a su alto rating del día domingo. En el extremo opuesto se encuentran las amas de casa con 5,81 puntos de rating promedio más de lunes a viernes que los sábado y los domingo. Sin duda, estas diferencias guardan relación con el factor trabajo antes mencionado. El Gráfico 2.18 muestra el rating promedio de lunes a viernes versus el promedio de sábado y domingo, según todos los grupos sociodemográficos analizados.

Los grupos de edad, por su parte, mantienen una tendencia equivalente de lunes a jueves, con el mayor consumo en los adultos mayores y el menor por parte de los niños. Sin embargo, el viernes y el sábado este último grupo sobrepasa a los dos grupos etarios inmediatamente superiores a él. El domingo, en tanto, los jóvenes vuelven a consumir mayor cantidad de televisión que los niños. Finalmente, destaca que la variable nivel socioeconómico no muestra una interacción estadísticamente significativa con el rating promedio diario, lo cual implica que no hay diferencias importantes en el consumo de los distintos segmentos, según los diferentes días de la semana (ver Cuadro 2.5).

\subsection{El Rating de grupos demográficos según franjas horarias}

A continuación abordaremos brevemente las principales variaciones de rating en las cinco franjas del día, según estación y promedio de lunes a viernes versus sábado y domingo. En primer lugar, es posible concluir que las tendencias generales antes detectadas con respecto al rating promedio según estación (mayor consumo en invierno, seguido de otoño, primavera y verano), se repiten $-y$, por ende, encuentran su origen- en prácticamente todos los grupos en las franjas vespertino y prime time. En las tres franjas restantes se desarrolla, en general, una baja variación del consumo televisivo entre estaciones. Esto también se registra en la variable 
nivel socioeconómico, aunque, como de costumbre, las diferencias entre sus categorías son comparativamente de menor orden. En cuanto a la excepción antes revisada, según la cual los adultos mayores y el grupo $\mathrm{ABC} 1$ eran los únicos que disminuían su rating de otoño a invierno, ésta se explica precisamente porque ambos grupos marcan dicha tendencia en la franja de mayor consumo del día: el prime time.

Por otra parte, es posible constatar que el leve mayor consumo televisivo de los hombres durante el fin de semana en relación al de los días laborales, se debe a sus mayores ratings en las franjas mediodía y sobremesa, vespertino y trasnoche. Cabe destacar que en esta última franja -que comienza a las 24:30 y termina a las 6:00 hrs.-, todos los grupos analizados registran un mayor rating promedio el fin de semana que de lunes a viernes. Respecto del total de las mujeres y de las amas de casa, destaca que en las cuatro restantes franjas del día obtienen un mayor rating los días laborales, alcanzado una proporción de 1,9 y 2,5 veces mayor consumo en la franja matinal, respectivamente.

En los grupos de edad, las franjas registran tendencias equivalentes entre sí en los promedios lunes a viernes versus sábado y domingo, con la excepción del vespertino, en el cual los jóvenes, los adultos y los adultos mayores obtienen mayor rating el fin de semana. Además, se constata que en la franja matinal los adultos y los adultos mayores consumen el doble de televisión en promedio de lunes a viernes que el sábado y el domingo. Por último, en los grupos socioeconómicos también se desarrollan tendencias particulares en la franja vespertino, puesto que los segmentos $A B C 1$ y C2 marcan un mayor rating el fin de semana que los días hábiles. En las demás franjas tienden a replicarse las tendencias generales antes revisadas.

\subsection{La distribución de los promedios de rating más altos y bajos del año}

Esta sección se discutirá, de forma exploratoria, la relación entre las variables estación del año, mes y día de la semana y los ratings anuales más altos y bajos de determinados horarios. La pregunta que se encuentra en el centro de estos análisis se refiere a la importancia de las variables temporales en la magnitud del consumo televisivo, en comparación con el factor oferta programática, es decir, los contenidos que emiten los canales de televisión. En otras palabras, se pretende determinar a grosso modo si la aparición de los promedios más altos de rating se explican correctamente por factores temporales o si debe introducirse una explicación adicional basada en factores programáticos.

En las páginas anteriores se concluyó que el prime time es en todas las fechas la franja de mayor consumo televisivo del día. Es por ello que la siguiente exploración se concentrará exclusivamente en dicha franja día. Con el fin de enriquecer el análisis, se observarán adicionalmente dos subfranjas del prime time, las cuales suscitan un especial interés por parte de los canales de televisión y las agencias de publicidad: el noticiero (21:00-22:00) y la primera serie (22:00-23:30). Específicamente, interesa determinar si la distribución de los promedios de rating más altos y bajos registrados en estos tres períodos horarios se comportan de modo similar a las variaciones del consumo televisivo según fechas, que fueron descritas en las secciones anteriores.

Un primer dato a tener en cuenta es el rating promedio más alto del año en un período de 15 minutos (15). Éste se desarrolló el día lunes 6 de agosto entre las 20:45 y las 21:00 hrs. y ascendió a 41,6 puntos. Si bien este peack se produjo en el segundo mes con mayor rating promedio del año, debe destacarse que, al mismo tiempo, correspondió a un día con programación extraordinaria, a saber, el de la emisión paralela del primer capítulo de las teleseries "Amores de Mercado" y "Piel Canela", de Televisión Nacional y Canal 13, 
respectivamente. Ambos espacios finalizaron dicho día, precisamente, en torno a las 21:00 hrs. Otro elemento que reafirma la importancia del factor programático en el mencionado peack anual, es que el mismo período de 15 minutos promedió el día anterior 37,9 puntos y el día siguiente sólo 37, es decir, índices claramente inferiores al primero.

Ahora bien, para determinar con mayor exactitud el peso de las variables temporales en el comportamiento del rating, debe considerarse información adicional a la del peack anual. El Cuadro 2.6 muestra la distribución del $10 \%$ más alto y más bajo de rating promedio en el prime time y sus subfranjas noticiero y primera serie, según estación del año, mes y día de la semana. Es posible constatar, en primer lugar, que la distribución de tanto el 10\% superior como del 10\% inferior tiende a coincidir en estos tres períodos del día, por lo cual es posible entregar conclusiones válidas para todos dichos períodos.

Se observa en el Cuadro 2.6 que los ratings promedio más elevados se dan en torno al $70 \%$ en invierno, mientras que los más bajos tienen lugar en más de un $80 \%$ en verano. Respecto de la distribución por meses, vemos que ésta también coincide fuertemente con los índices mensuales revisados más arriba, según los cuales antes y después de julio el consumo televisivo total disminuye. En cuanto a los días de la semana, por último, los promedios más altos se presentan preferentemente de lunes a miércoles, seguidos de jueves y domingo. El $10 \%$ más bajo, en tanto, se distribuye en primer lugar los días sábado, seguido de los domingos y los viernes. Estos datos también concuerdan, en general, con los promedios anuales de la franja prime time según día de la semana (ver Cuadro 2.1).

La información anterior permite concluir que la distribución de los promedios de rating más altos y bajos del año es coincidente con la estructura de la evolución de este índice a partir de las variables temporales estación, mes y día de la semana. Ahora bien, esta constatación puede parecer a primera vista como evidente. No obstante, podría ser fácilmente rebatible si se hubiese comprobado que los mayores y menores índices de rating se distribuyen más de acuerdo a la oferta programática, como sería el caso, por ejemplo, de encontrar un mayor porcentaje de los ratings más altos del año asociados a emisiones ocurridas los meses de verano o los días sábado. Debe aclararse, sin embargo, que tal como comprobamos en relación al peack anual de 15 minutos -a lo cual puede agregársele que el mayor rating anual en la subfranaja noticiero ocurrió el día del ataque terrorista a los EE.UU-, la importancia del factor programático no puede calificarse marginal, aunque al parecer sí tendría menor influencia que la variable temporal.

\subsection{La dispersión temporal de los promedios de rating total en la franja prime time}

Una nueva aproximación que permite explorar la relación entre el comportamiento del rating y las variables temporales, tiene su base en el coeficiente de variación, que se define como la desviación estándar de una muestra de datos dividida por su media. Se considera que un coeficiente de variación menor a 0,5 refleja una alta homogeneidad de los datos estudiados. El Cuadro 2.7 detalla el coeficiente de variación del rating promedio en el prime time, el noticiero y la primera serie a lo largo de todo año 2001 y, además, según tres agrupaciones de días alternativas: de lunes a viernes, de lunes a jueves, y de lunes a jueves sin contar los días feriados y las vísperas de feriados. Es posible constatar que en todos estos casos se obtienen valores menores a 0,5 (Cuadro 2.7). Además, destaca que, a medida que la agrupación diaria se va haciendo más específica, el coeficiente de variación disminuye tanto en el prime time como en sus dos subfranjas. Así, como era de esperarse, los datos de los días de lunes a jueves que excluyen las jornadas inusuales, resultan ser los mayormente homogéneos entre sí. 
La relación entre el comportamiento del rating y las variables temporales puede profundizarse si se distinguen los coeficientes de variación a partir de las variables estación del año, mes y día de la semana. Si éstos índices registran valores significativamente más bajos que el promedio anual, se tendrá un nuevo argumento para sostener la importancia del factor fecha en los promedios de rating. El Cuadro 2.8 muestra los coeficientes de variación correspondientes a la agrupación de días más homogénea antes revisada -lunes a jueves sin feriados ni vísperas de feriados-, según las tres variables temporales estudiadas. Es posible constatar que la dispersión más baja se da, por lejos, en el caso de los meses. En efecto, el coeficiente de variación se sitúa en los tres períodos horarios estudiados, salvo contadas excepciones, entre 3 y $10 \%$. Esto implica que, no obstante las diferencias en la oferta programática, el porcentaje de televisores encendidos registra una variación muy baja dentro de cada mes en dichas horas del día. En febrero las tres franjas muestran sus coeficientes de variación más elevados, lo cual puede explicarse en parte por un efecto programático concreto: el Festival de Viña, certamen que durante sus seis días de transmisión distorsiona enormemente el consumo televisivo mensual.

Los coeficientes de variación de las estaciones otoño e invierno, en tanto, también son fuertemente menores a la media anual. En verano e primavera, en tanto, se registran niveles más altos de variación del rating, aunque sin llegar superar al índice anual. Por último, debe destacarse que los días de la semana no muestran coeficientes de variación significativamente menores al valor anual, y que en algunos casos incluso lo superan. Esto lleva a concluir que el mes es la variable temporal que mejor refleja la variación de los promedios de rating del prime time, el noticiero y la primera serie de los días usuales de lunes a jueves. En otras palabras, si estudiamos el consumo televisivo que se realiza en estas tres franjas horarias los días usuales de un mes específico, debiéramos registrar magnitudes muy homogéneas entre sí -y ciertamente menos dispersas que la media anual-, independiente de la oferta programática que se haya emitido. En el otro extremo se encuentra la variable día de la semana, la cual no muestran niveles de homogeneidad en los promedios de rating muy distantes de la media anual.

\subsection{Conclusiones}

En las páginas anteriores hemos investigado la estructura del consumo televisivo que realizó en Chile el año 2001 el total de la población y 12 segmentos específicos de ella, a lo largo del año 2001. De este modo, detectamos empíricamente cómo varía el rating de cada uno de estos grupos de acuerdo con diversas variables temporales y de franjas horarias, aproximación que sólo resulta posible gracias a un registro electrónico y continuo en el tiempo del comportamiento de las audiencias de televisión. Se pudo constatar que el consumo televisivo total alcanza su mayor expresión en invierno, mientras que en verano desciende a su punto mínimo. Coincidentemente, febrero y julio son los meses extremos en cuanto a las cifras de rating: 10,86 y 15,19 puntos, respectivamente. Por otra parte, observamos una gran similitud en los índices anuales de audiencia de los cinco días hábiles, al tiempo que el sábado registró el menor consumo de la semana. La curva de exposición televisiva diaria, en tanto, señala dos marcadas cúspides: alrededor de las 15:00 hrs. y en torno a las 22:30 hrs. Es así como la franja de mayor consumo del día es, por lejos, el prime time, seguido de las franjas vespertino y mediodía/sobremesa. Como pudimos constatar, el rating promedio que registran estas franjas a lo largo del año ayuda a entender de mejor modo las variaciones según estaciones, meses y días de la semana que se dan en todos los grupos analizados.

Las diferencias en el consumo televisivo según las variables sociodemográficas tradicionales, muestran que las mujeres ven en promedio más televisión que los hombres, que los adultos mayores superan con creces a los demás grupos etarios, y que el segmento $D$ marca mayores 
ratings que los restantes niveles socioeconómicos. El mayor promedio anual, por su parte, corresponde a las amas de casa sin trabajo. Es muy interesante notar el hecho de que las diferencias entre niveles socioeconómicos muestran una considerable mayor homogeneidad en comparación con lo que sucede con las categorías de las variables sexo y edad. Por otra parte, si bien no se registró un consumo televisivo mayor a medida que crecen las variables edad y nivel socioeconómico, las tendencias detectadas se encuentran muy cercanas a dicha tendencia.

Las dos últimas secciones de este apartado exploraron la importancia de las variables temporales estación del año, mes y día de la semana en la magnitud del consumo televisivo realizado en la franja prime time y sus subfranjas noticiero y primera serie. Se concluyó que la distribución de los promedios de rating más altos y bajos del año es coincidente con la estructura de la evolución de este índice a partir de las tres variables temporales consideradas. Asimismo, se observó que el mes es la variable temporal que mejor atenúa la variación de los promedios de rating en estos períodos horarios de los días usuales de lunes a jueves. Todas estas conclusiones aluden directa e indirectamente al fenómeno de las rutinas que se generan en torno al consumo televisivo a lo largo de un año.

El análisis llevado a cabo en este estudio representa un aporte importante al conocimiento teórico sobre el tipo de exposición televisiva que se lleva a cabo actualmente en Chile. A diferencia de lo que ocurre en otros países, en nuestro país no se han realizado mayores aproximaciones de las presentes características a los datos de consumo televisivo que son registrados electrónicamente. Al comparar nuestros resultados con las nociones referentes al consumo televisivo detectadas por estudios foráneos, resulta que éstas son, en general, acordes con los registros nacionales. No obstante, queda pendiente la tarea de confrontar con mayor profundidad la estructura del consumo televisivo de Chile con la de otros países. Al mismo tiempo, aparece como un desafío futuro y necesario -para un análisis más específico del comportamiento de las audiencias de televisión- incorporar variables independientes adicionales a las que entrega actualmente el sistema People Meter. En efecto, factores tales como el tipo de trabajo desempeñado, el número de personas que viven en el hogar y la posesión de otras tecnologías de la comunicación y la información, permitirían comprender de una manera más exhaustiva las variaciones en las cifras de rating aquí descritas.

\section{Bibliografía}

ANG, I. (1996). Living room wars : Rethinking media audiences for a postmodern world. Routledge, Londres y Nueva York.

CALLEJO GALLEGO, J. (1995). La audiencia activa. El consumo televisivo: discursos y estrategias. Centro de Investigaciones Sociológicas, Madrid.

CASSETI, F. Y DI CHIO, F. (1999). Análisis de la televisión : Instrumentos, métodos y prácticas de investigación. Paidós, Barcelona.

FAJNZYLBER, R. (1997). Una experiencia en semiótica animada. Pontificia Universidad Católica de Chile, Serie de Talleres Instituto de Sociología, Santiago de Chile.

GANS, H. (1980). Deciding what's news : A study of CBS Evening News, NBC Nightly News, Newsweek and Time. Vintage Books, Nueva York.

HUERTAS, A. (1998). Cómo se miden las audiencias en televisión. Editorial CIMS, Barcelona. 
JAUSET, J. (2000). La investigación de audiencias en televisión. Editorial Paidós, Barcelona.

MARSCHALL, P. (1997). Los ratings de televisión y el efecto zapping. Revista de Administración y Economía UC, Santiago de Chile.

MCQUAIL, D. (2000). Introducción a la teoría de la comunicación de masas (segunda edición). Editorial Paidós, Barcelona.

NIELSEN MEDIA RESEARCH (2000). 2000 Report on television. Nueva York.

PAÚL, C. (1998). Estudio y estimación de ratings de teleseries y medición de su influencia en noticieros. Memoria para optar al título de Ingeniero Civil de Industrias con Diploma en Ingeniería Mecánica, Santiago de Chile.

POSTMAN, N. y POWERS, S. (1992). How to watch TV news. Penguin Books, Nueva York.

TIME-IBOPE (1998). Anexo metodológico : Estudio de audiencia en televisión 1999 - 2003. Santiago de Chile.

WEBSTER, J. \& PHALEN, P. (1997). The mass audiences : Rediscovering the dominant model. Lawrence Erlbaum Associates, New Yersey.

\& LICHTY, L. (2000). Rating analysis: The theory and practice of audiencia research (segunda edición). Lawrence Erlbaum Associates, New Yersey.

\section{Anexo: Gráficos y Cuadros}


Rating Total Promedio Según Estaciones del Año

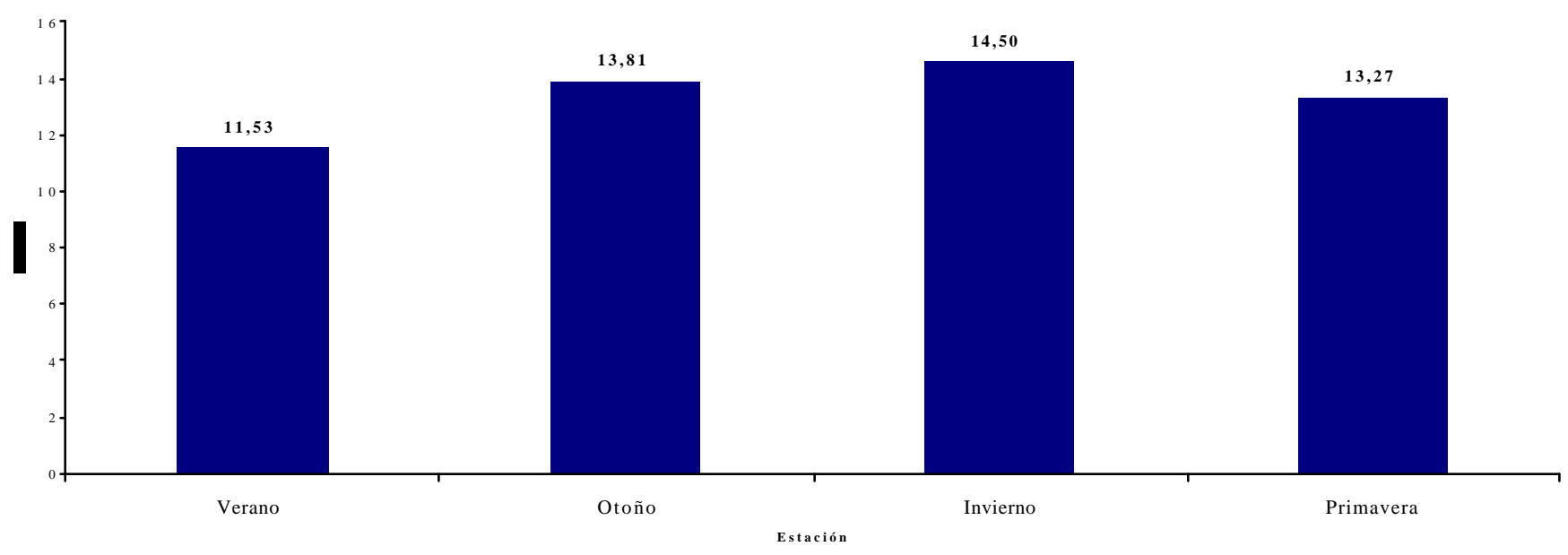

GRÁFICO 2.2

Rating Total Promedio Según Meses

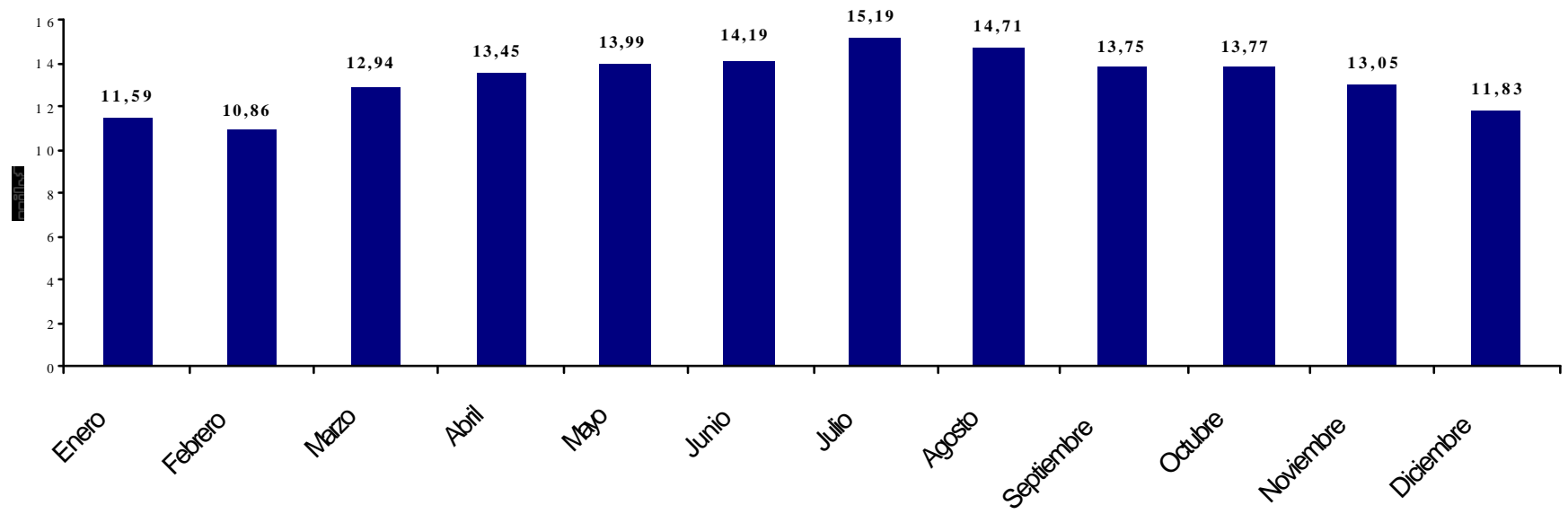

Meses

GRÁFICO 2.3

Rating Total Promedio Según Días de la Semana

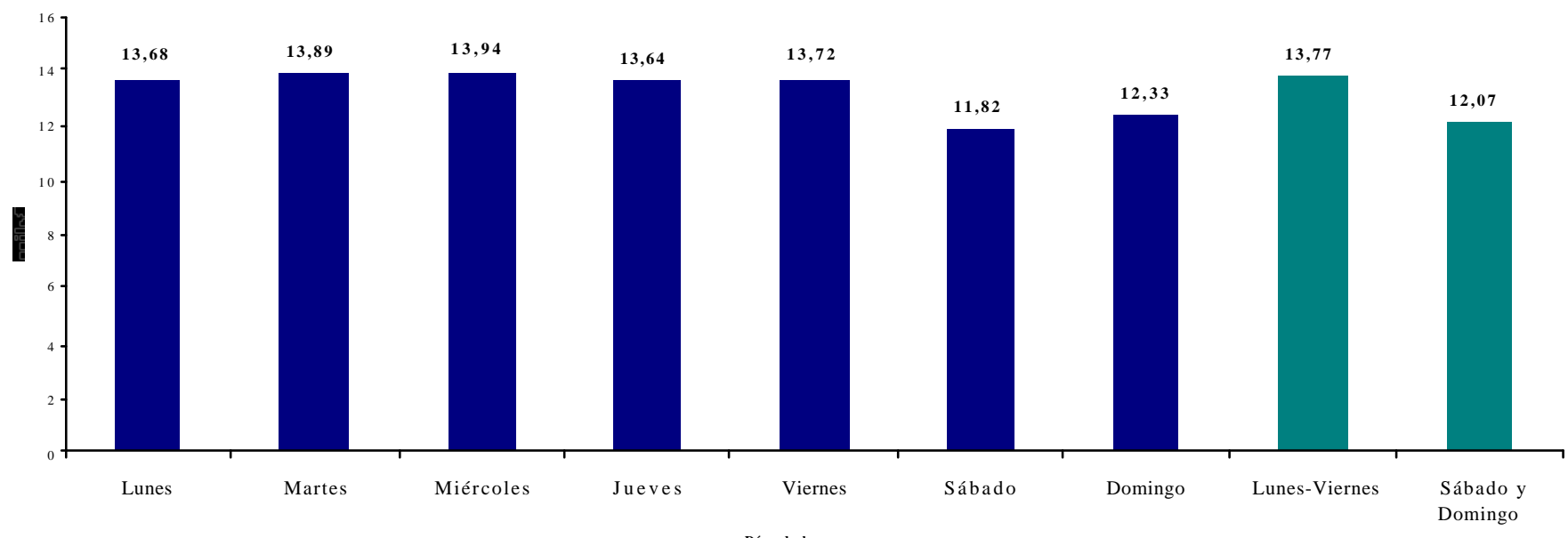


Revista Mad. No.7. Septiembre 2002. Departamento de Antropología. Universidad de Chile http://rehue.csociales.uchile.cl/publicaciones/mad/07/paper07.pdf

GRÁFICO 2.4

Evolución Diaria de Rating Total (períodos de $15 \mathrm{~min}$ ) Promedio Anual

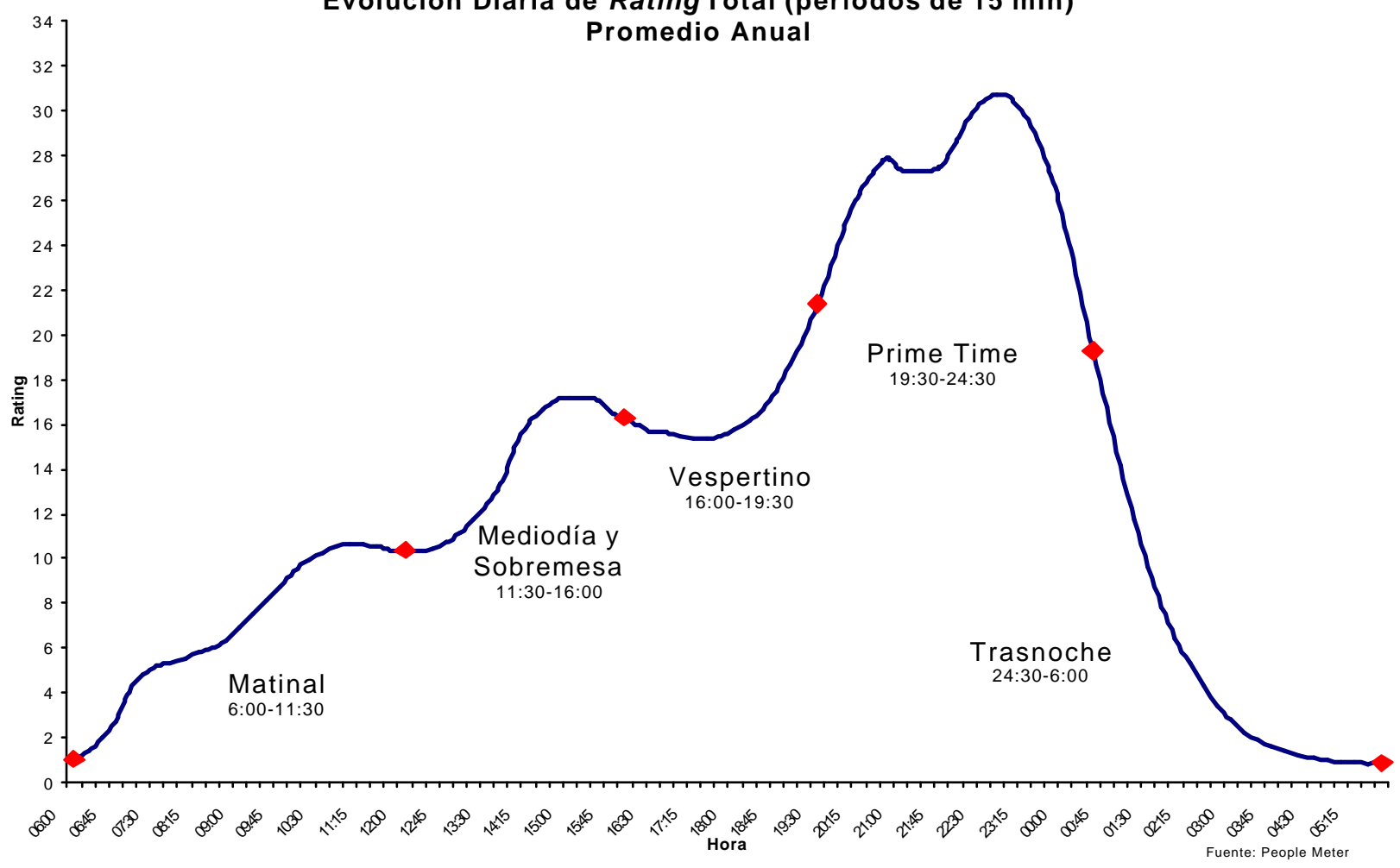

$\stackrel{w}{\sigma}$

23 
Revista Mad. No.7. Septiembre 2002. Departamento de Antropología. Universidad de Chile http://rehue.csociales.uchile.cl/publicaciones/mad/07/paper07.pdf

GRÁFICO 2.5

Rating Promedio Diario Anual Según Grupos

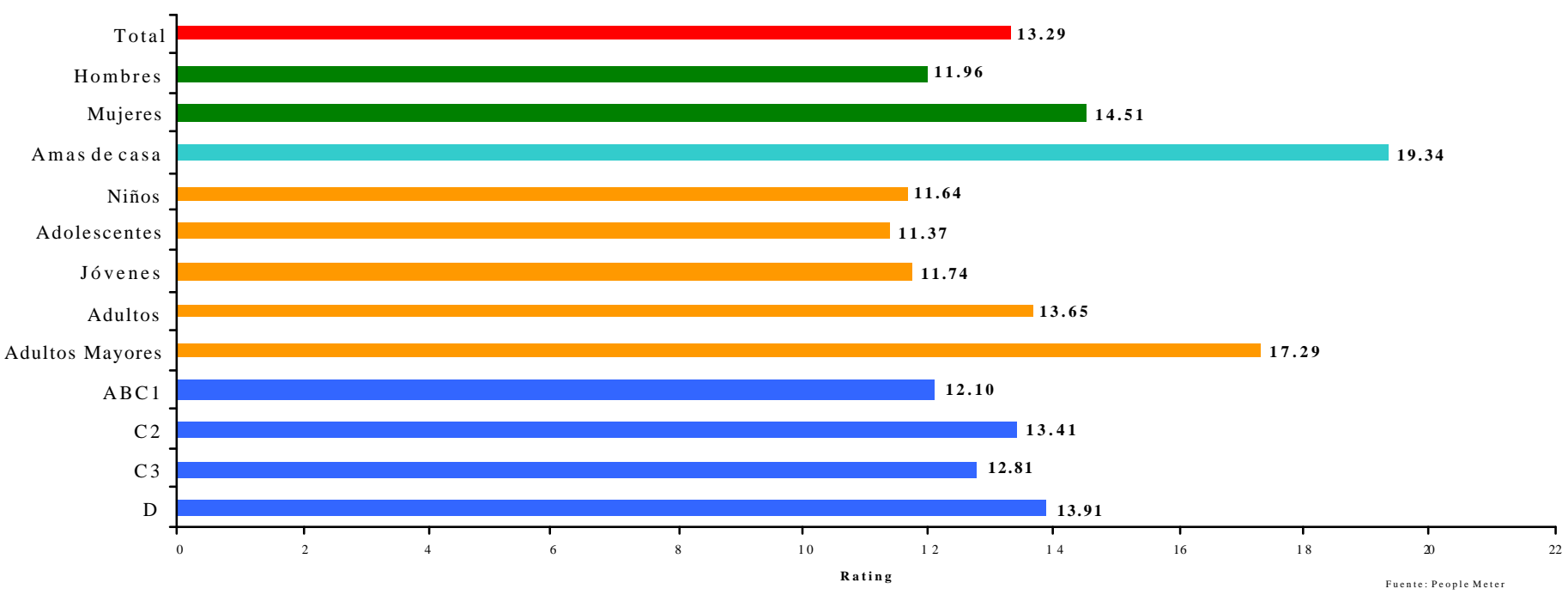


GRÁFICO 2.6

Evolución Diaria de Rating Según Sexo y Amas de Casa

Promedio Anual

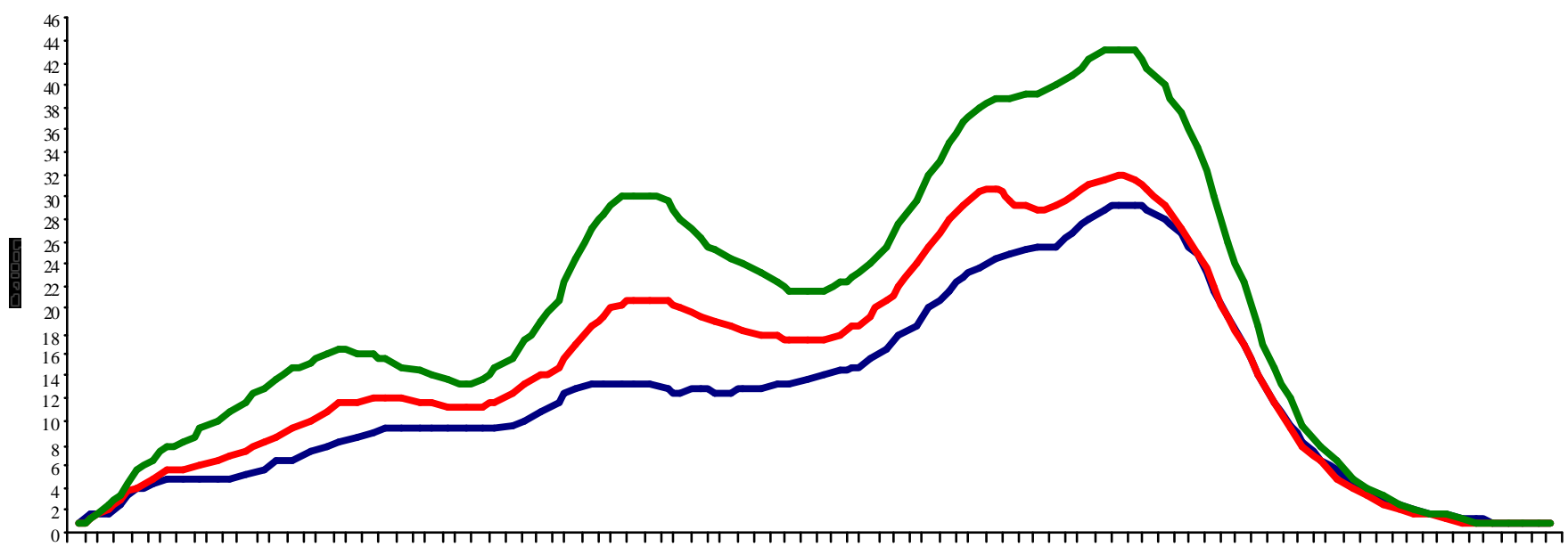

"

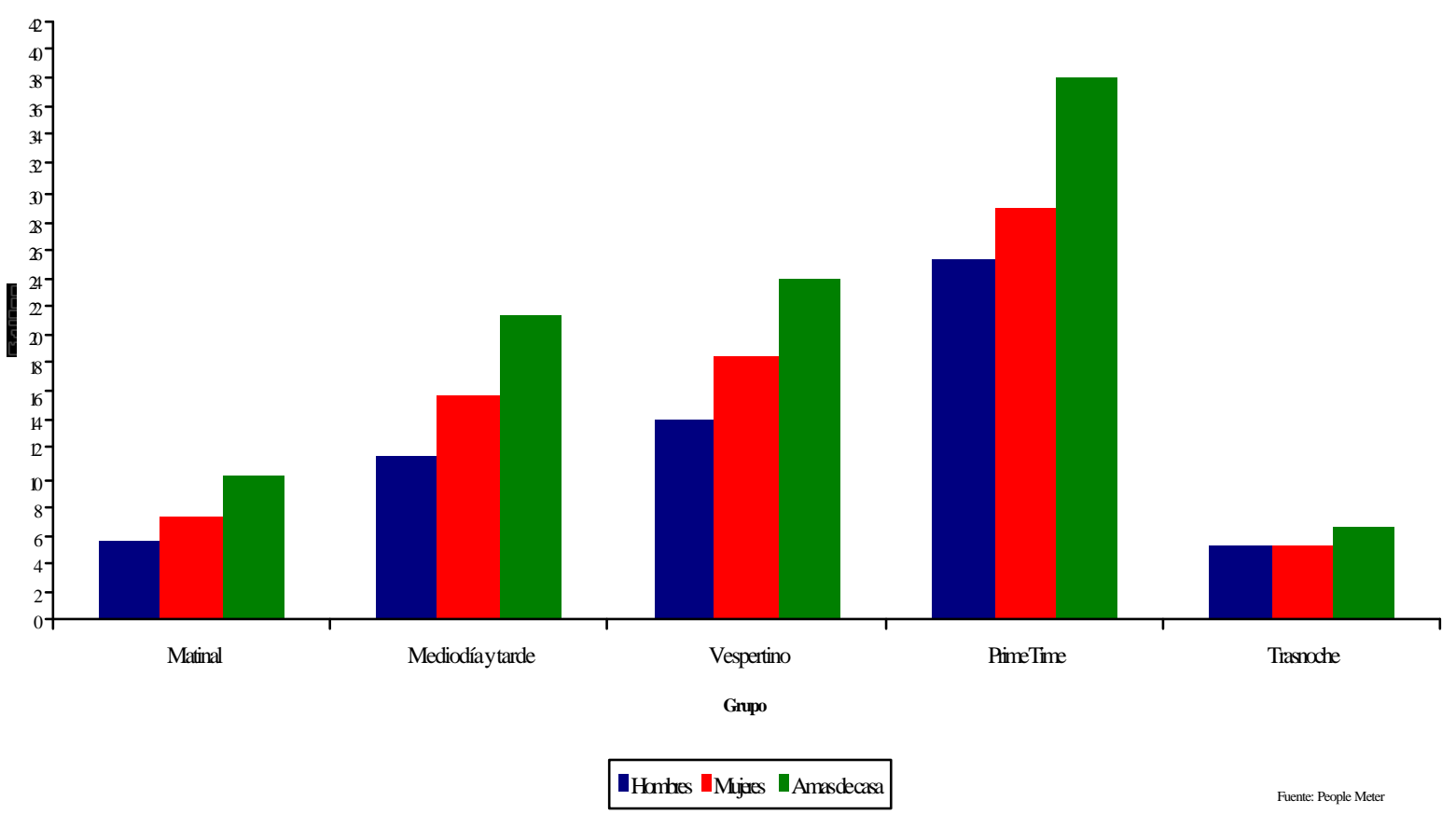


GRÁFICO 28

Evolución Diaria de Rating Según Grupos de Edad

Promedio Anual

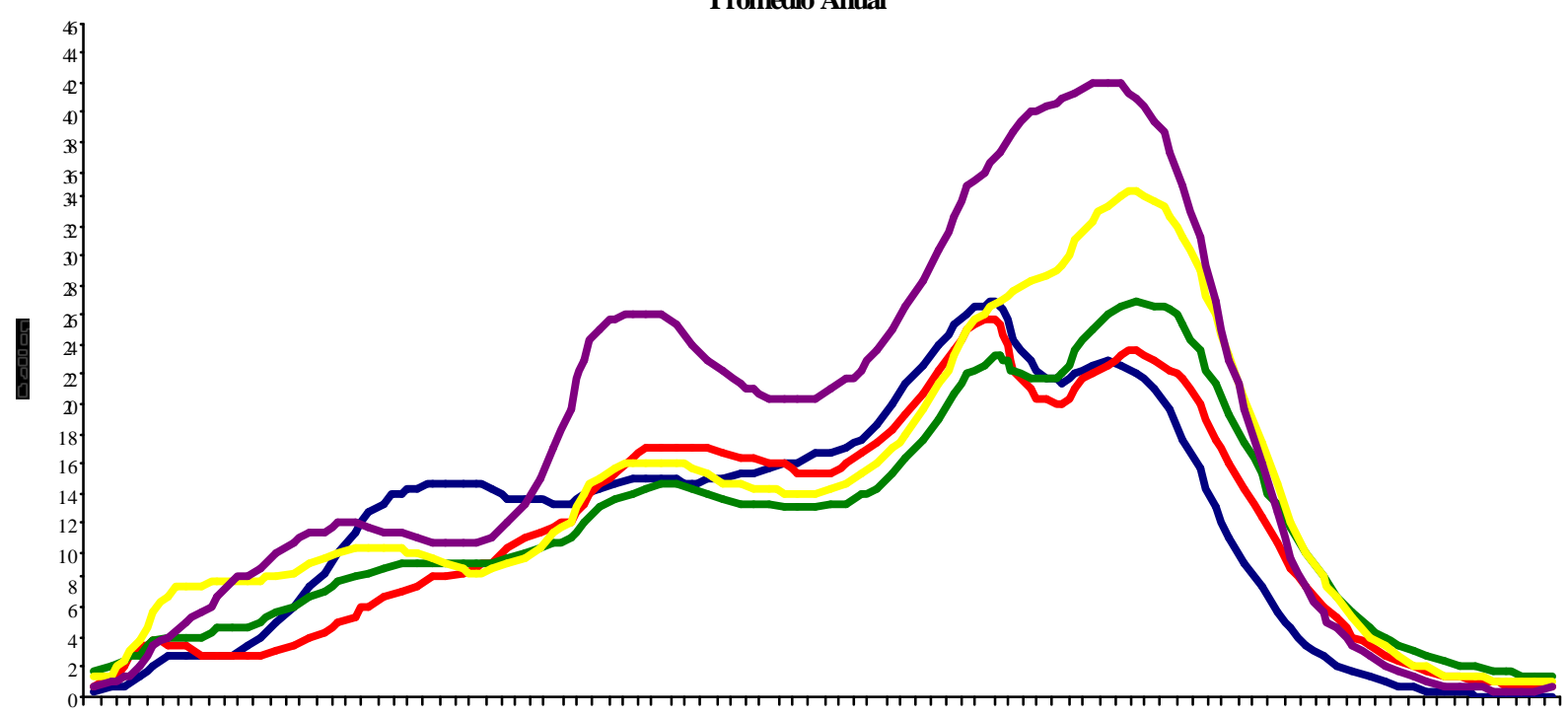

舟

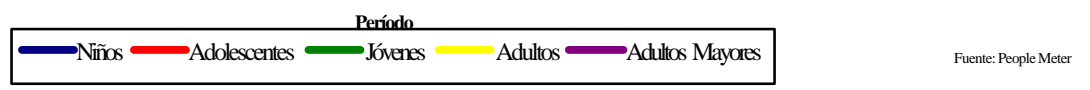

GRÁFICO 29

Rating Promedio por Franjas Según Grupo de Edad

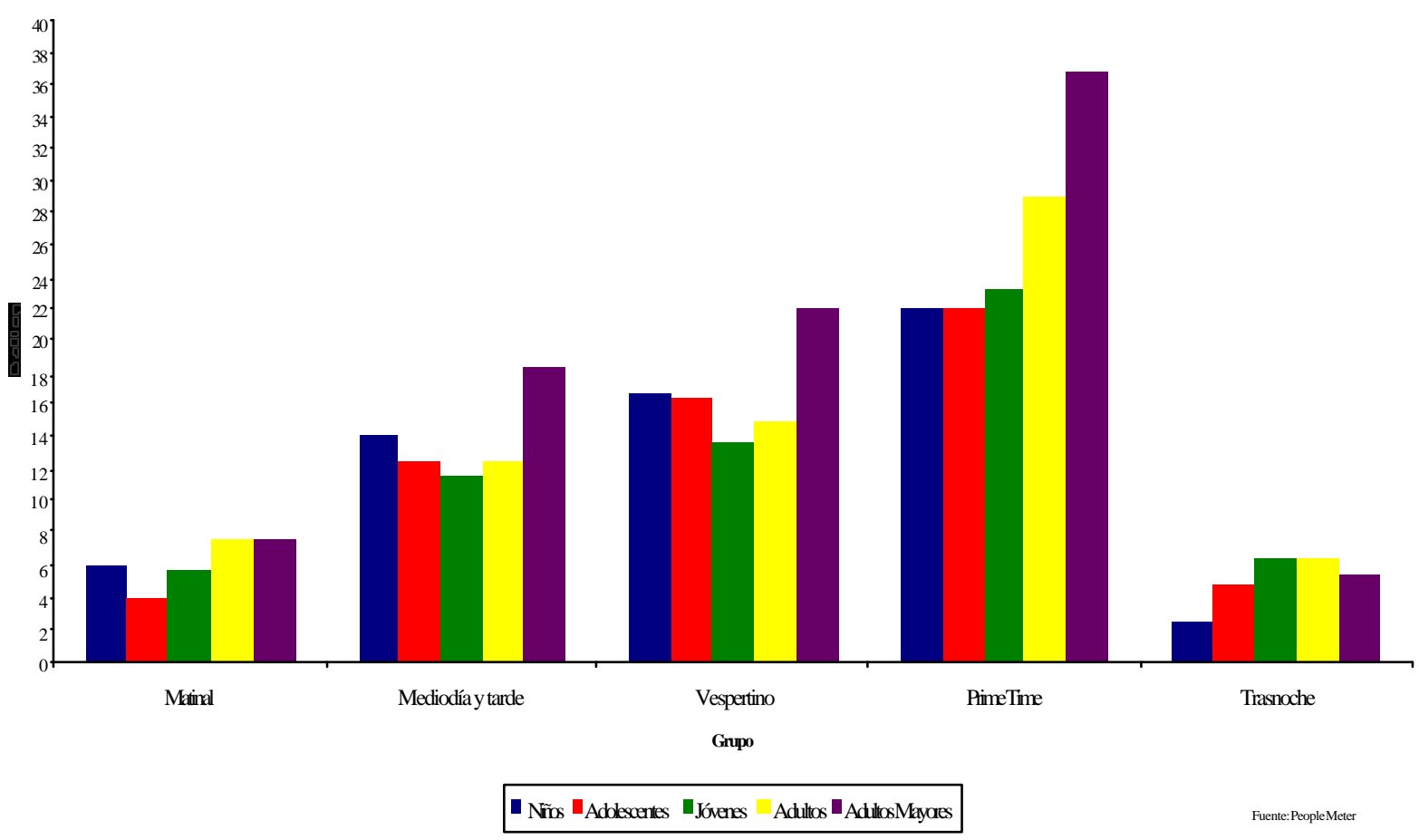


GRÁFICO 2.10

Evolución Diaria deRating Según Nivel Socioeconómico

Promedio Anual

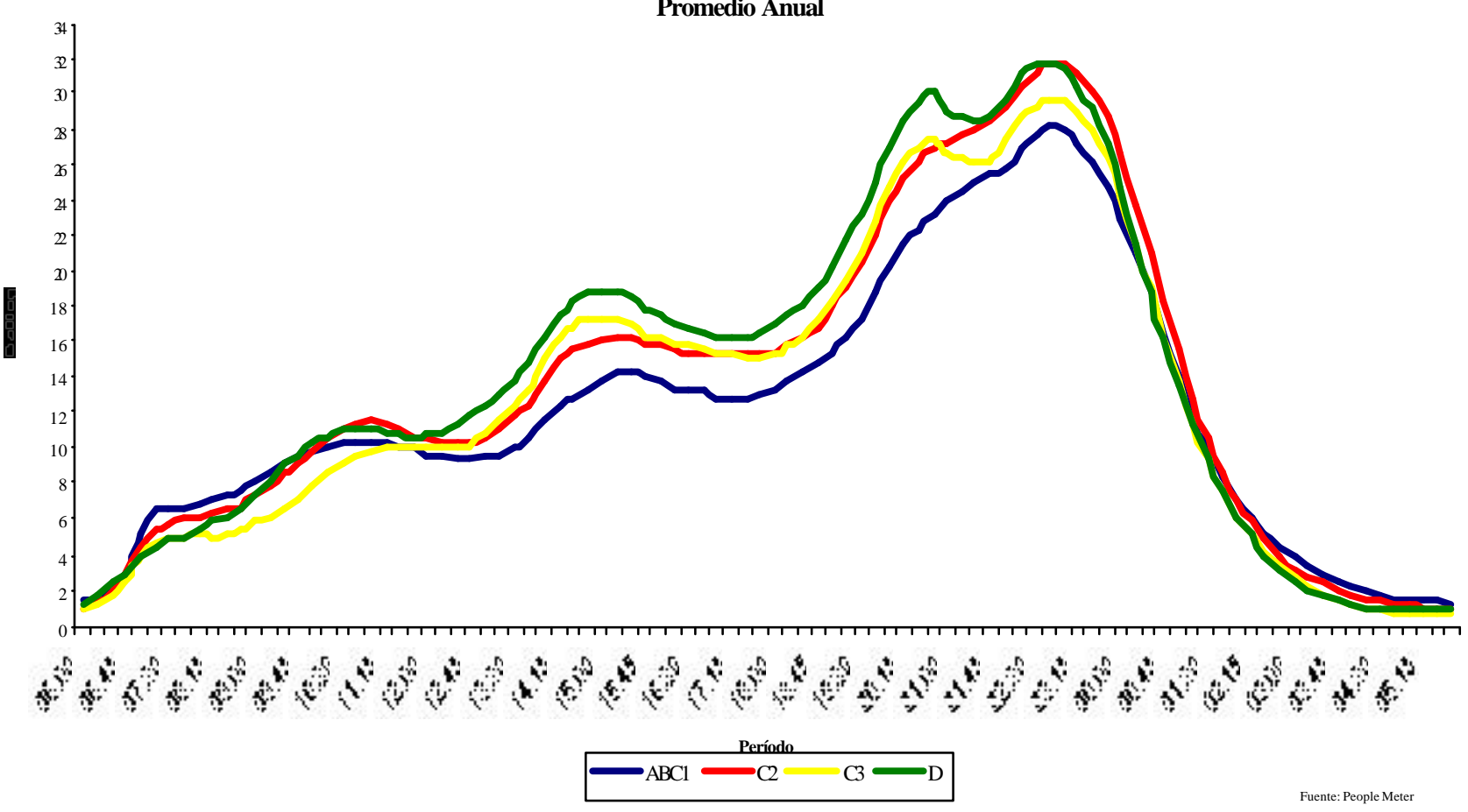

GRÁFICO 211

Rating Promedio por Franjas Según Nivel Socioeconómico

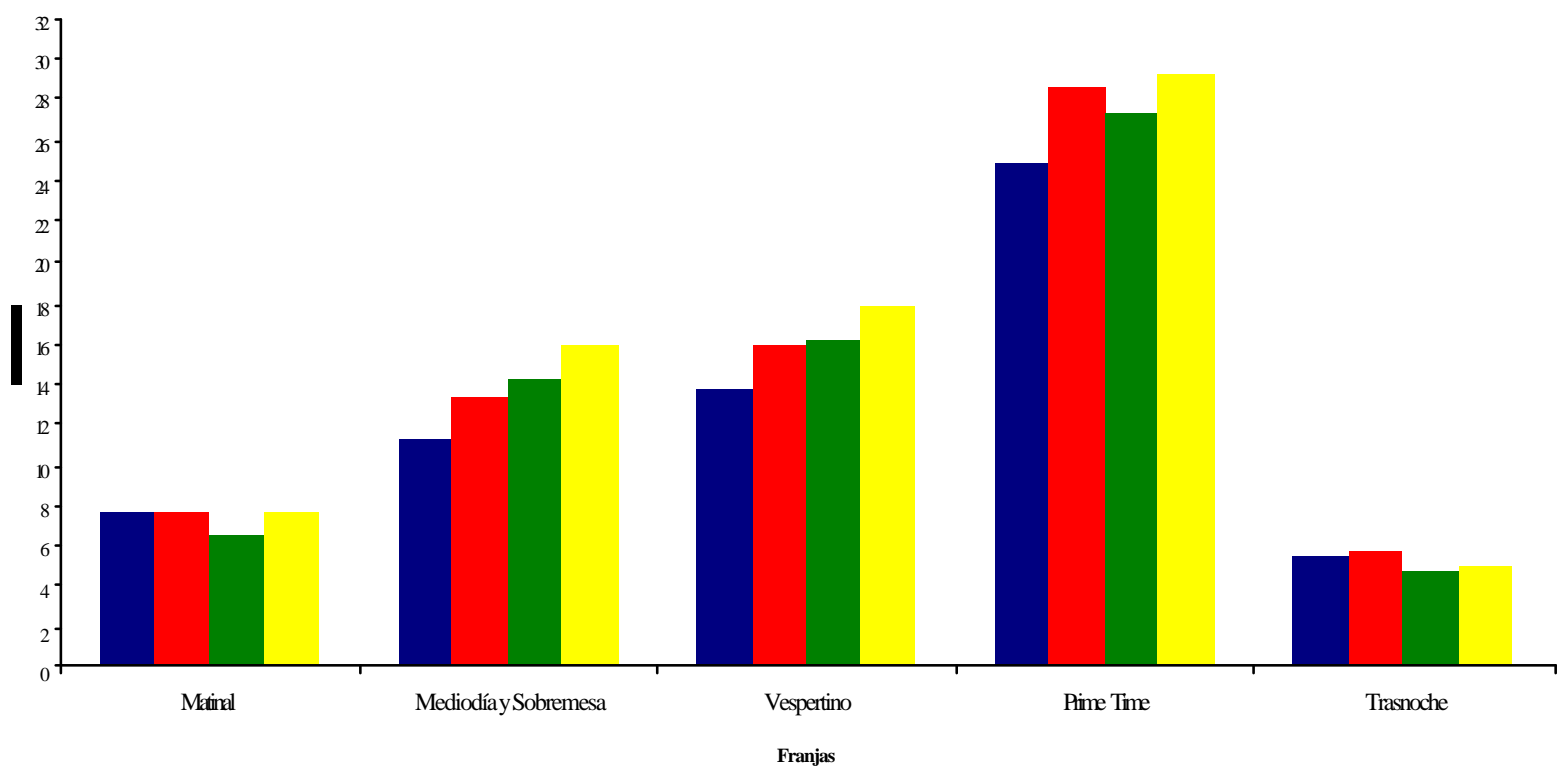

$\square \mathrm{ABC} \square \mathrm{C} \triangle \mathrm{C} \backsim \mathrm{D}$ 
Revista Mad. No.7. Septiembre 2002. Departamento de Antropología. Universidad de Chile http://rehue.csociales.uchile.cl/publicaciones/mad/07/paper07.pdf

GRÁFICO 2.12

Rating Según Sexo por Estaciones del Año

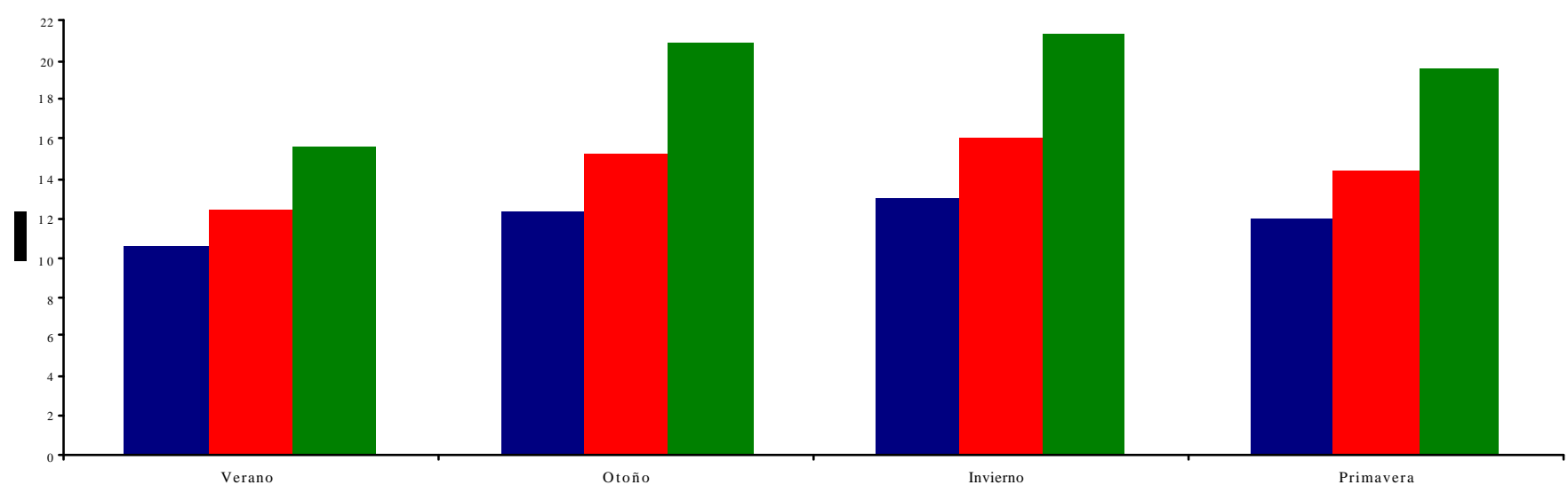

Estación

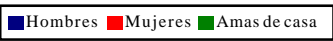

GRÁFICO 2.13

Rating Según Edad por Estaciones del Año

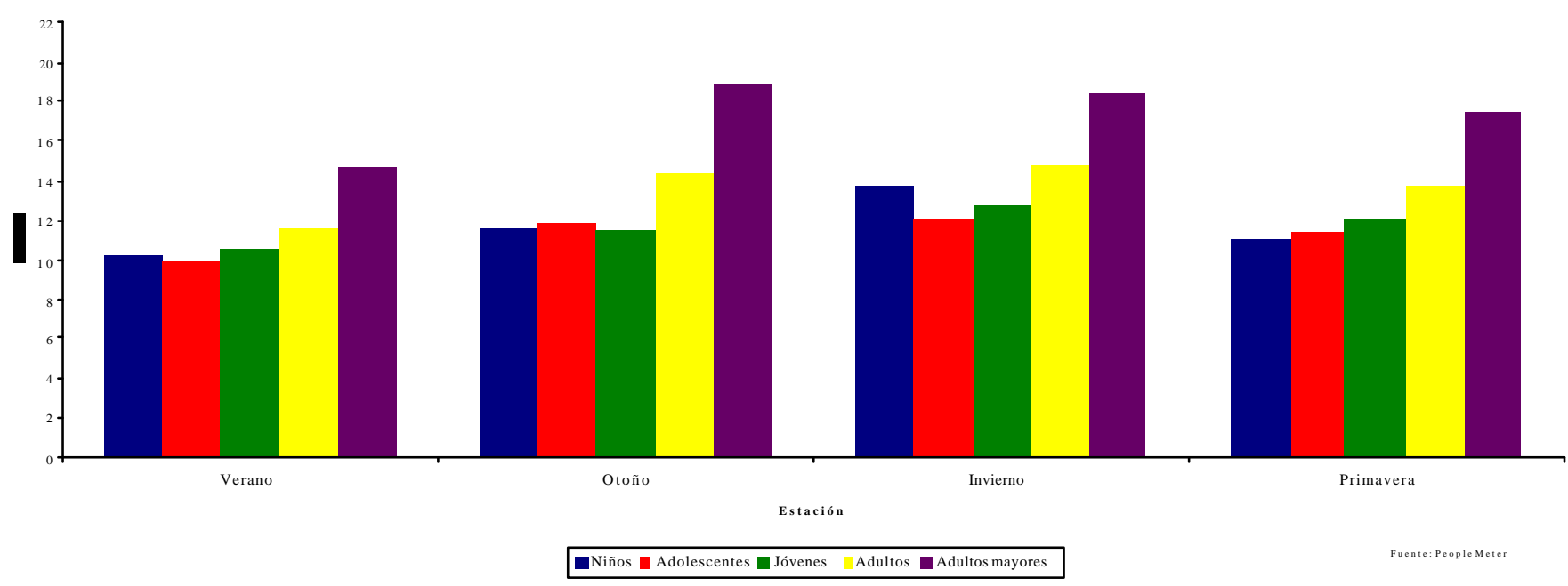

GRÁFICO 2.14

Rating Según Nivel Socioeconómicopor Estaciones del Año

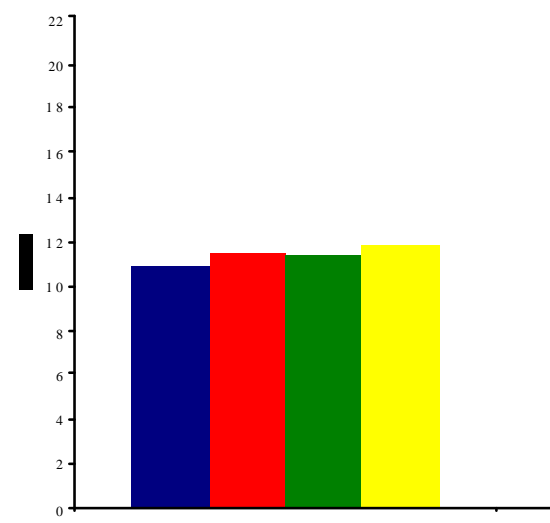

Verano

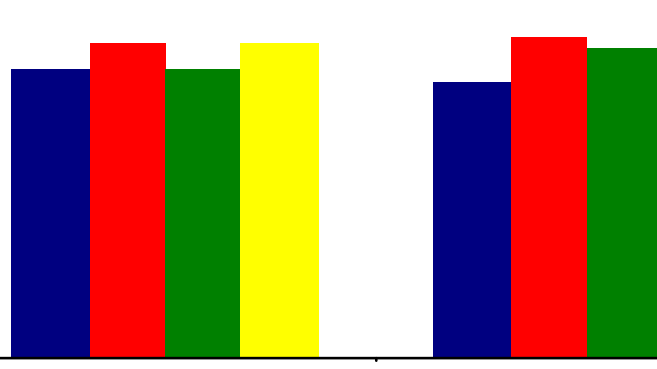

Invierno

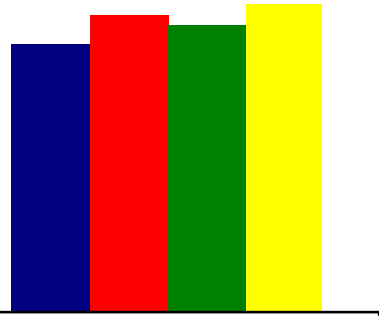

Primavera

Estación 



GRÁFICO 2.15 Rating Según Sexo por Meses

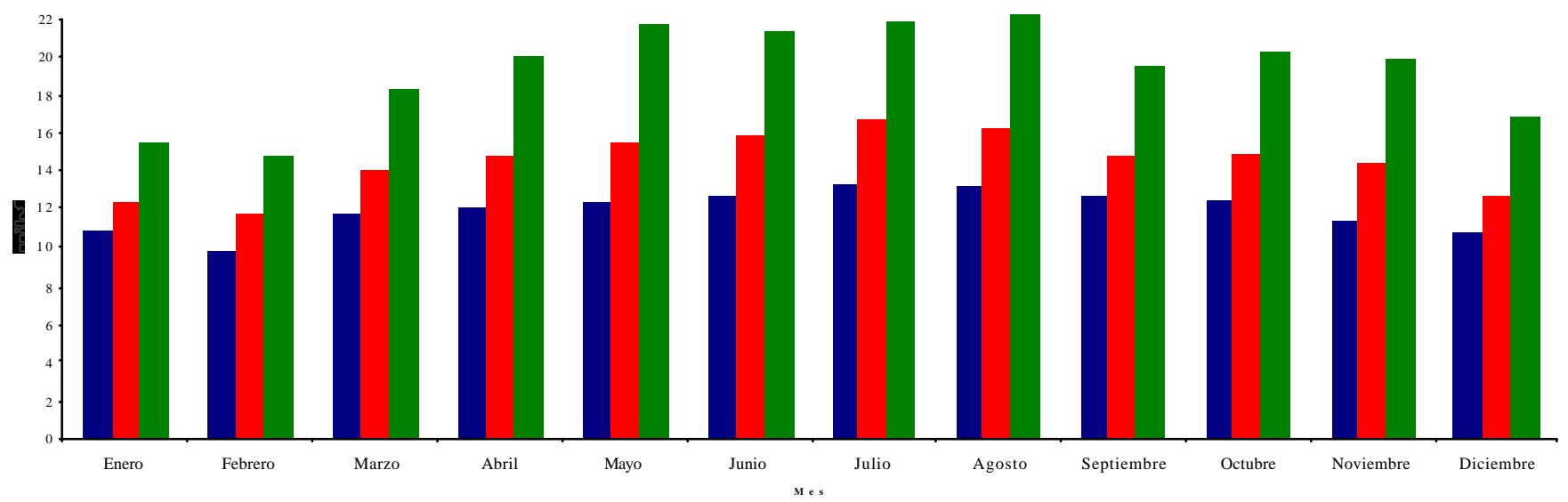

- Hombres $\square$ Mujeres $\square$ Amasdecasa

GRÁFICO 2.16

Rating Según Edad por Meses

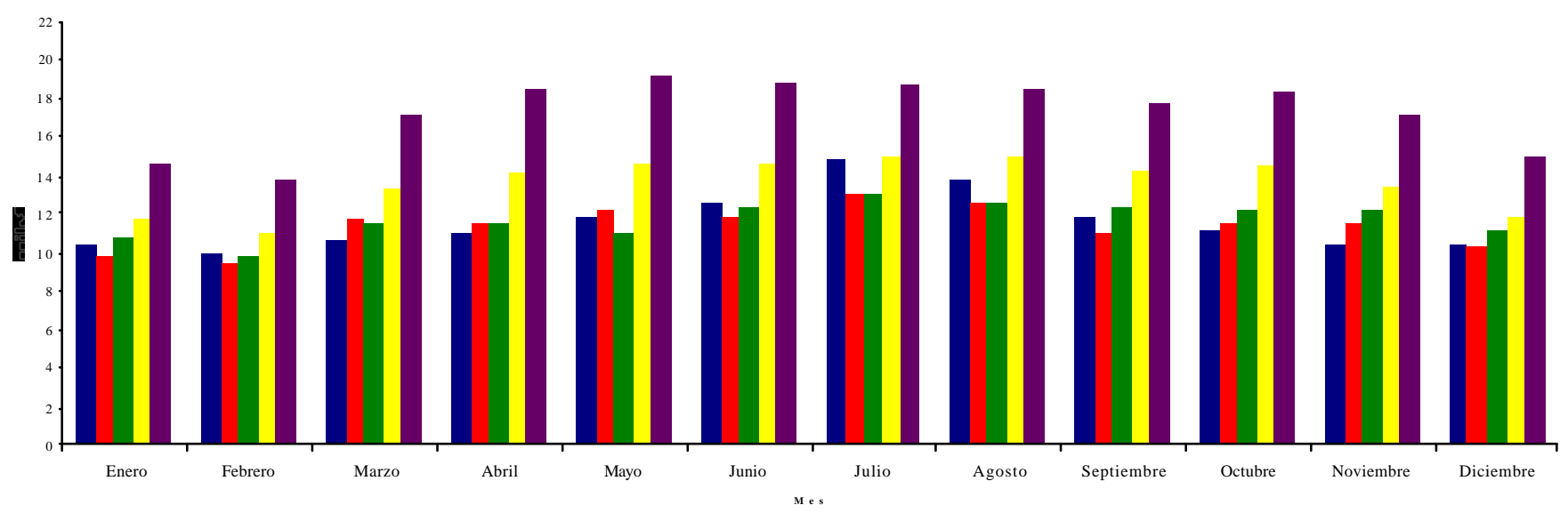

- Niños $\mathbf{W}^{\text {Adolescentes }} \mathbf{W}^{\text {Jóvenes }}$ Adultos $\boldsymbol{Q}^{\text {Adultos mayores }}$

GRÁFICO 2.17

Rating Según Nivel Socioeconómico por Meses

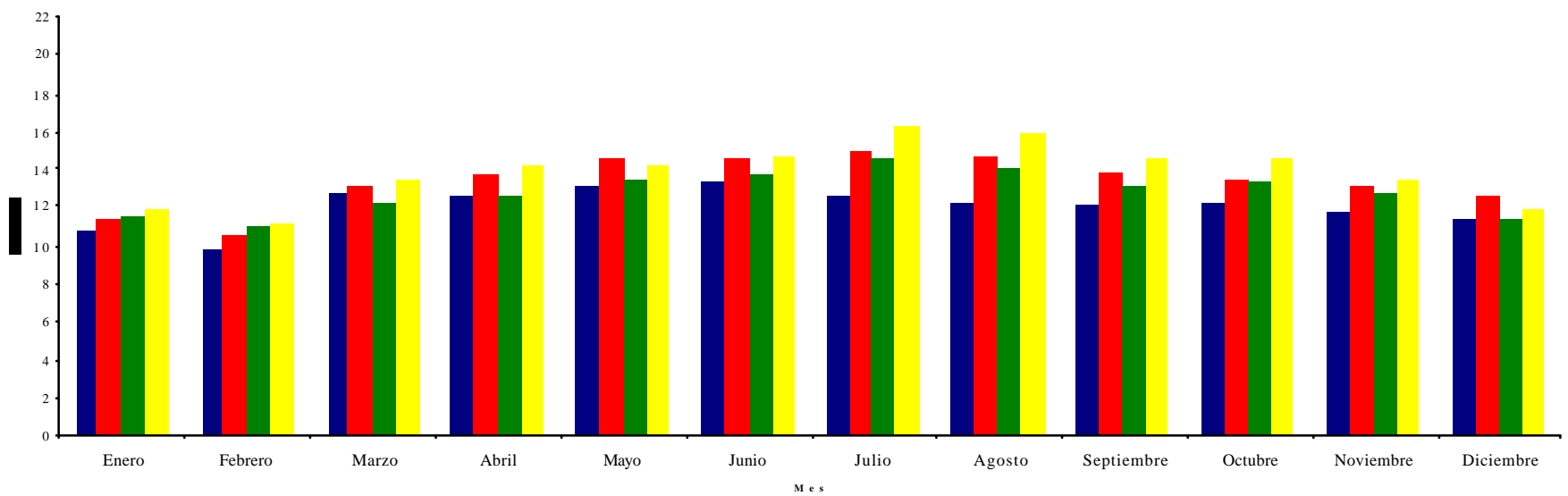


Revista Mad. No.7. Septiembre 2002. Departamento de Antropología. Universidad de Chile http://rehue.csociales.uchile.cl/publicaciones/mad/07/paper07.pdf

GRÁFICO 2.18

Rating por Grupos Sociodemográficos Según Promedio Lunes a Viernes Versus Sábado y Domingo

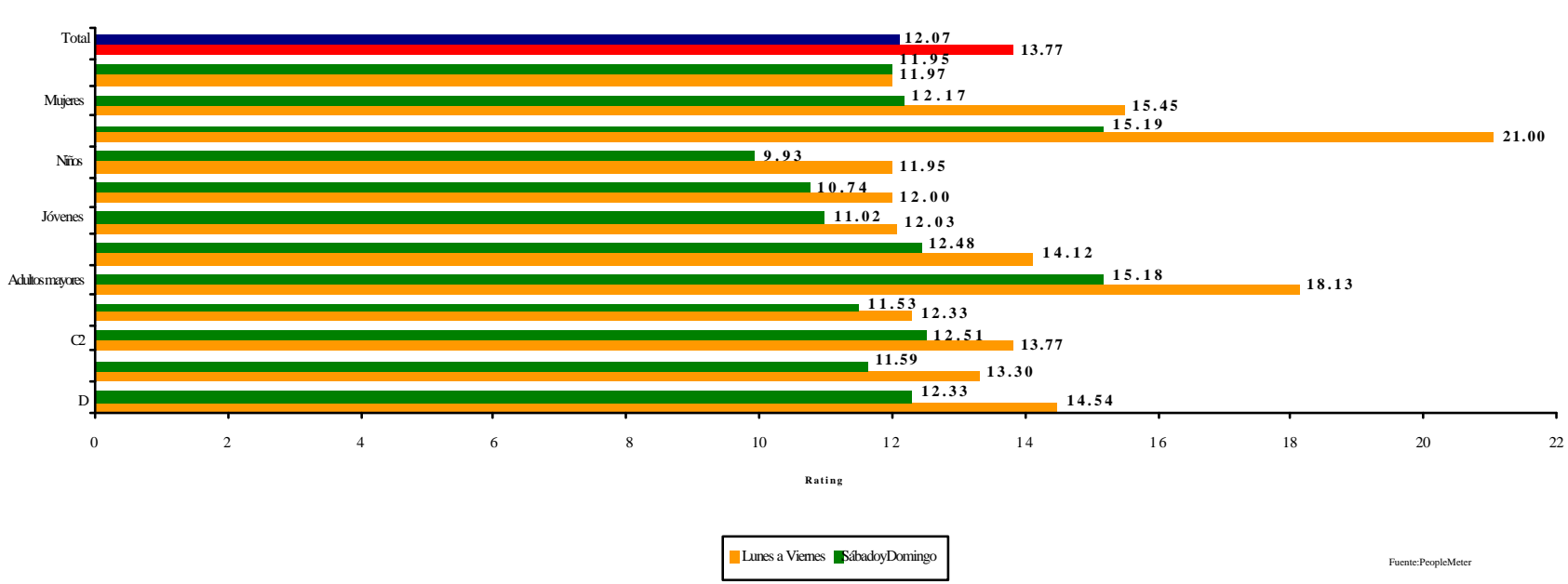


Cuadro 2.1: Promedio Anual de Rating Total Según Fechas y Franjas

\begin{tabular}{|c|c|c|c|c|c|c|c|}
\hline & & $\begin{array}{c}\text { Promedio } \\
\text { Día }\end{array}$ & Matinal & $\begin{array}{l}\text { Mediodía / } \\
\text { Sobremesa }\end{array}$ & Vespertino & Prime Time & Trasnoche \\
\hline & AÑO 2001 & 13.29 & 6.51 & 13.57 & 16.42 & 27.14 & 5.26 \\
\hline \multirow{4}{*}{$\begin{array}{l}\text { 동 } \\
\frac{0}{0} \\
\frac{0}{0} \\
\\
\end{array}$} & Verano & 11.53 & 5.11 & 13.08 & 13.90 & 21.82 & 5.81 \\
\hline & Otoño & 13.81 & 6.84 & 13.77 & 17.58 & 29.07 & 4.55 \\
\hline & Invierno & 14.50 & 7.03 & 14.12 & 18.40 & 30.46 & 5.30 \\
\hline & Primavera & 13.27 & 7.03 & 13.28 & 15.74 & 27.09 & 5.37 \\
\hline \multirow{12}{*}{$\stackrel{g}{d}$} & Enero & 11.59 & 4.90 & 13.70 & 13.83 & 21.72 & 5.91 \\
\hline & Febrero & 10.86 & 4.61 & 12.50 & 12.64 & 20.01 & 6.31 \\
\hline & Marzo & 12.94 & 6.53 & 13.61 & 16.08 & 26.15 & 4.79 \\
\hline & Abril & 13.45 & 6.86 & 13.74 & 16.95 & 27.88 & 4.46 \\
\hline & Mayo & 13.99 & 6.76 & 13.97 & 17.92 & 29.66 & 4.49 \\
\hline & Junio & 14.19 & 6.70 & 13.52 & 18.31 & 30.43 & 4.85 \\
\hline & Julio & 15.19 & 6.91 & 15.52 & 19.66 & 31.37 & 5.64 \\
\hline & Agosto & 14.71 & 7.47 & 13.79 & 18.52 & 31.38 & 5.13 \\
\hline & Septiembre & 13.75 & 7.14 & 13.26 & 16.86 & 28.64 & 5.23 \\
\hline & Octubre & 13.77 & 7.33 & 13.62 & 16.25 & 28.56 & 5.30 \\
\hline & Noviembre & 13.05 & 6.85 & 13.04 & 15.38 & 26.69 & 5.35 \\
\hline & Diciembre & 11.83 & 5.93 & 12.47 & 14.40 & 22.67 & 5.70 \\
\hline \multirow{7}{*}{ 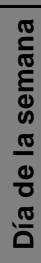 } & Lunes & 13.68 & 6.75 & 14.18 & 16.34 & 28.73 & 4.82 \\
\hline & Martes & 13.89 & 7.29 & 14.50 & 16.83 & 28.42 & 4.91 \\
\hline & Miércoles & 13.94 & 7.46 & 14.44 & 16.74 & 28.57 & 4.93 \\
\hline & Jueves & 13.64 & 7.51 & 14.21 & 16.40 & 27.72 & 4.74 \\
\hline & Viernes & 13.72 & 7.54 & 14.22 & 15.98 & 26.82 & 6.12 \\
\hline & Sábado & 11.82 & 4.70 & 11.28 & 15.80 & 22.86 & 6.82 \\
\hline & Domingo & 12.33 & 4.32 & 12.13 & 16.87 & 26.80 & 4.45 \\
\hline
\end{tabular}

Nota: Efectos de interacción estadísticamente significativos al 1\% en negritas

Cuadro 2.2: Rating Promedio Anual por Grupos Sociodemográficos Según Franjas

\begin{tabular}{|l|c|ccccc|}
\cline { 2 - 7 } \multicolumn{1}{c|}{} & $\begin{array}{c}\text { Promedio } \\
\text { Día }\end{array}$ & Matinal & $\begin{array}{c}\text { Mediodía / } \\
\text { Sobremesa }\end{array}$ & Vespertino & Prime Time & Trasnoche \\
\hline Total & 13.29 & 6.51 & 13.57 & 16.42 & 27.14 & 5.26 \\
\hline Hombres & 11.96 & 5.59 & 11.31 & 14.08 & 25.27 & 5.41 \\
Mujeres & 14.51 & 7.36 & 15.64 & 18.58 & 28.86 & 5.11 \\
\hline Amas de casa & 19.34 & 10.43 & 21.35 & 23.84 & 38.21 & 6.61 \\
\hline Niños & 11.64 & 5.86 & 14.26 & 16.83 & 22.07 & 2.51 \\
Adolescentes & 11.37 & 3.89 & 12.57 & 16.48 & 22.15 & 4.83 \\
Jóvenes & 11.74 & 5.57 & 11.50 & 13.72 & 23.28 & 6.37 \\
Adultos & 13.65 & 7.47 & 12.26 & 14.95 & 28.76 & 6.41 \\
Adultos mayores & 17.29 & 7.57 & 18.39 & 22.10 & 36.85 & 5.27 \\
\hline ABC1 & 12.10 & 7.15 & 11.34 & 13.82 & 24.00 & 5.76 \\
C2 & 13.41 & 6.89 & 12.96 & 15.99 & 27.56 & 5.79 \\
C3 & 12.81 & 5.67 & 13.42 & 16.15 & 26.41 & 4.99 \\
D & 13.91 & 6.74 & 14.67 & 17.60 & 28.31 & 5.01 \\
\hline
\end{tabular}

Nota: Efectos de interacción estadísticamente significativos al 1\% en negritas 
Cuadro 2.3: RatingPromedio Anual Por Grupos Sociodemográficos Según Estaciones y Franjas

\begin{tabular}{|c|c|c|c|c|c|c|c|}
\hline & & $\begin{array}{l}\text { Promedio } \\
\text { Día }\end{array}$ & Matinal & $\begin{array}{l}\text { Mediodía / } \\
\text { Sobremesa }\end{array}$ & Vespertino & Prime Time & Trasnoche \\
\hline \multirow{4}{*}{ 흉 } & Verano & 11.53 & 5.11 & 13.08 & 13.90 & 21.82 & 5.81 \\
\hline & Otoño & 13.81 & 6.84 & 13.77 & 17.58 & 29.07 & 4.55 \\
\hline & Invierno & 14.50 & 7.03 & 14.12 & 18.40 & 30.46 & 5.30 \\
\hline & Primavera & 13.27 & 7.03 & 13.28 & 15.74 & 27.09 & 5.37 \\
\hline \multirow{4}{*}{ 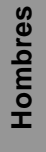 } & Verano & 10.62 & 4.66 & 11.07 & 12.49 & 20.52 & 6.01 \\
\hline & Otoño & 12.26 & 5.77 & 11.19 & 14.96 & 26.69 & 4.79 \\
\hline & Invierno & 12.96 & 5.92 & 11.95 & 15.52 & 28.14 & 5.41 \\
\hline & Primavera & 11.96 & 5.98 & 11.03 & 13.30 & 25.61 & 5.45 \\
\hline \multirow{4}{*}{ 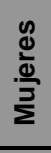 } & Verano & 12.37 & 5.53 & 14.93 & 15.20 & 23.02 & 5.63 \\
\hline & Otoño & 15.24 & 7.83 & 16.15 & 19.99 & 31.25 & 4.34 \\
\hline & Invierno & 15.92 & 8.05 & 16.11 & 21.06 & 32.60 & 5.21 \\
\hline & Primavera & 14.47 & 8.00 & 15.36 & 17.98 & 28.44 & 5.29 \\
\hline \multirow{4}{*}{ 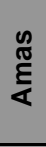 } & Verano & 15.57 & 7.58 & 18.35 & 18.07 & 29.66 & 6.87 \\
\hline & Otoño & 20.83 & 11.69 & 23.21 & 26.62 & 41.57 & 5.47 \\
\hline & Invierno & 21.27 & 11.28 & 21.93 & 27.13 & 43.40 & 6.87 \\
\hline & Primavera & 19.64 & 11.13 & 21.84 & 23.40 & 38.00 & 7.25 \\
\hline \multirow{4}{*}{ 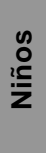 } & Verano & 10.26 & 4.46 & 14.94 & 15.17 & 16.56 & 3.37 \\
\hline & Otoño & 11.63 & 5.63 & 12.96 & 17.59 & 23.77 & 1.71 \\
\hline & Invierno & 13.60 & 6.87 & 16.00 & 19.53 & 26.78 & 2.61 \\
\hline & Primavera & 11.04 & 6.44 & 13.14 & 14.96 & 21.03 & 2.36 \\
\hline \multirow{4}{*}{$\frac{\text { d }}{\frac{0}{0}}$} & Verano & 10.01 & 3.15 & 13.15 & 13.52 & 17.29 & 5.43 \\
\hline & Otoño & 11.88 & 3.96 & 13.02 & 17.89 & 23.75 & 4.25 \\
\hline & Invierno & 12.16 & 4.04 & 12.39 & 18.26 & 24.57 & 4.94 \\
\hline & Primavera & 11.40 & 4.38 & 11.72 & 16.17 & 22.88 & 4.70 \\
\hline \multirow{4}{*}{ 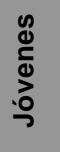 } & Verano & 10.59 & 4.59 & 11.28 & 12.43 & 19.63 & 6.66 \\
\hline & Otoño & 11.50 & 5.47 & 11.04 & 13.87 & 24.02 & 5.02 \\
\hline & Invierno & 12.66 & 6.24 & 11.86 & 14.78 & 25.24 & 6.93 \\
\hline & Primavera & 12.20 & 5.97 & 11.82 & 13.77 & 24.18 & 6.86 \\
\hline \multirow{8}{*}{  } & Verano & 11.71 & 5.83 & 11.55 & 12.61 & 23.00 & 6.87 \\
\hline & Otoño & 14.39 & 8.18 & 13.05 & 16.07 & 30.68 & 5.80 \\
\hline & Invierno & 14.77 & 7.86 & 12.55 & 16.78 & 32.25 & 6.35 \\
\hline & Primavera & 13.70 & 7.99 & 11.87 & 14.28 & 28.98 & 6.64 \\
\hline & Verano & 14.60 & 5.93 & 16.01 & 16.97 & 30.79 & 5.90 \\
\hline & Otoño & 18.85 & 8.36 & 19.79 & 24.81 & 40.53 & 5.08 \\
\hline & Invierno & 18.29 & 7.79 & 18.59 & 24.54 & 39.89 & 4.92 \\
\hline & Primavera & 17.35 & 8.18 & 19.11 & 21.96 & 36.03 & 5.17 \\
\hline \multirow{5}{*}{ 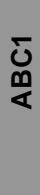 } & Verano & 10.86 & 5.53 & 11.22 & 12.36 & 19.82 & 6.80 \\
\hline & Otoño & 13.10 & 7.92 & 11.83 & 15.05 & 27.00 & 5.46 \\
\hline & Invierno & 12.34 & 7.33 & 11.13 & 14.33 & 25.36 & 5.23 \\
\hline & Primavera & 12.07 & 7.79 & 11.18 & 13.51 & 23.73 & 5.57 \\
\hline & Verano & 11.46 & 5.30 & 12.17 & 13.44 & 21.66 & 6.51 \\
\hline \multirow{4}{*}{ ชิ } & Otoño & 14.26 & 7.52 & 13.60 & 17.28 & 30.06 & 5.27 \\
\hline & Invierno & 14.50 & 7.44 & 13.48 & 17.60 & 30.80 & 5.62 \\
\hline & Primavera & 13.36 & 7.28 & 12.55 & 15.59 & 27.58 & 5.77 \\
\hline & Verano & 11.32 & 4.92 & 13.30 & 13.94 & 21.06 & 5.57 \\
\hline \multirow{4}{*}{$\mathcal{O}$} & Otoño & 13.12 & 6.03 & 13.25 & 16.88 & 27.70 & 4.48 \\
\hline & Invierno & 13.90 & 5.71 & 13.97 & 18.07 & 29.67 & 5.03 \\
\hline & Primavera & 12.88 & 5.99 & 13.16 & 15.65 & 27.09 & 4.87 \\
\hline & Verano & 11.90 & 5.02 & 13.99 & 14.55 & 22.99 & 5.31 \\
\hline \multirow{3}{*}{0} & Otoño & 14.27 & 6.75 & 14.81 & 19.00 & 30.10 & 3.93 \\
\hline & Invierno & 15.57 & 7.70 & 15.45 & 20.26 & 32.30 & 5.35 \\
\hline & Primavera & 13.85 & 7.46 & 14.40 & 16.52 & 27.74 & 5.45 \\
\hline
\end{tabular}

Nota: Efectos de interacción estadísticamente significativos al 1\% en negritas; efectos de interacción estadísticamente significativos al $5 \%$ en cursivas 
Cuadro 2.4: Rating Promedio Anual por Grupos Sociodemográficos Según Meses y Franjas

\begin{tabular}{|c|c|c|c|c|c|c|c|c|c|c|c|c|c|c|c|}
\hline & & \begin{tabular}{|c|}
$\begin{array}{c}\text { Promedio } \\
\text { Dia }\end{array}$ \\
\end{tabular} & Matinal & $\begin{array}{l}\text { Mediodía/ } \\
\text { Sobremesa }\end{array}$ & Vespertino & Prime Time & Trasnoche & & & $\begin{array}{c}\text { Promedio } \\
\text { Día }\end{array}$ & Matinal & $\begin{array}{l}\text { Mediodía/ } \\
\text { Sobremesa }\end{array}$ & Vespertino & Prime Time & Trasnoche \\
\hline \multirow{12}{*}{$\begin{array}{l}\text { @ } \\
\text { ఏँ } \\
\text { है } \\
\text { ㅁ }\end{array}$} & Enero & 10.88 & 4.85 & 11.55 & 12.60 & 20.81 & 6.26 & \multirow{12}{*}{$\begin{array}{l}\text { on } \\
\frac{0}{3} \\
\frac{0}{2}\end{array}$} & Enero & 11.73 & 5.38 & 11.90 & 12.47 & 23.18 & 7.05 \\
\hline & Febrero & 9.81 & 4.05 & 10.43 & 11.11 & 18.62 & 6.21 & & Febrero & 10.99 & 5.32 & 11.17 & 11.31 & 20.85 & 7.35 \\
\hline & Marzo & 11.69 & 5.63 & 11.30 & 14.09 & 24.23 & 5.14 & & Marzo & 13.31 & 7.81 & 12.82 & 14.80 & 26.96 & 5.84 \\
\hline & Abril & 12.06 & 5.81 & 11.33 & 14.67 & 25.83 & 4.72 & & Abril & 14.08 & 8.22 & 13.08 & 15.69 & 29.54 & 5.67 \\
\hline & Mayo & 12.33 & 5.66 & 11.24 & 15.19 & 27.09 & 4.62 & & Mayo & 14.70 & 8.18 & 13.23 & 16.18 & 31.82 & 5.93 \\
\hline & Junio & 12.61 & 5.70 & 11.01 & 15.32 & 27.96 & 5.17 & & Junio & 14.62 & 7.99 & 12.47 & 16.69 & 31.91 & 5.97 \\
\hline & Julio & 13.37 & 5.74 & 13.11 & 16.10 & 28.36 & 5.86 & & Julio & 15.04 & 7.47 & 13.23 & 17.37 & 32.65 & 6.59 \\
\hline & Agosto & 13.16 & 6.24 & 11.69 & 15.62 & 29.20 & 5.12 & & Agosto & 15.03 & 8.50 & 12.40 & 16.84 & 33.07 & 6.17 \\
\hline & Septiembre & 12.60 & 6.37 & 11.44 & 14.84 & 27.06 & 5.23 & & Septiembre & 14.33 & 7.82 & 12.01 & 16.09 & 31.10 & 6.36 \\
\hline & Octubre & 12.48 & 6.22 & 11.32 & 13.86 & 27.17 & 5.45 & & Octubre & 14.43 & 8.31 & 12.48 & 15.00 & 30.99 & 6.74 \\
\hline & Noviembre & 11.51 & 5.56 & 10.43 & 12.54 & 25.01 & 5.41 & & Noviembre & 13.50 & 7.96 & 11.86 & 14.10 & 28.35 & 6.52 \\
\hline & Diciembre & 10.82 & 5.09 & 10.77 & 12.74 & 21.38 & 5.77 & & Diciembre & 11.87 & 6.55 & 10.36 & 12.59 & 24.14 & 6.81 \\
\hline \multirow{12}{*}{ 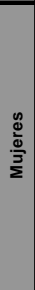 } & Enero & 12.24 & 4.95 & 15.68 & 14.96 & 22.55 & 5.59 & \multirow{12}{*}{ 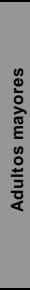 } & Enero & 14.63 & 5.85 & 16.14 & 16.81 & 31.16 & 5.76 \\
\hline & Febrero & 11.82 & 5.12 & 14.41 & 14.04 & 21.29 & 6.39 & & Febrero & 13.70 & 5.26 & 14.85 & 15.37 & 28.76 & 6.43 \\
\hline & Marzo & 14.09 & 7.36 & 15.74 & 17.92 & 27.92 & 4.47 & & Marzo & 17.11 & 7.90 & 17.97 & 20.96 & 36.69 & 5.37 \\
\hline & Abril & 14.73 & 7.83 & 15.96 & 19.05 & 29.76 & 4.23 & & Abril & 18.39 & 8.22 & 19.76 & 24.68 & 38.89 & 4.83 \\
\hline & Mayo & 15.52 & 7.78 & 16.47 & 20.42 & 32.01 & 4.36 & & Mayo & 19.18 & 8.48 & 20.63 & 24.94 & 41.15 & 5.07 \\
\hline & Junio & 15.74 & 7.78 & 15.92 & 21.12 & 32.93 & 4.50 & & Junio & 18.78 & 7.90 & 18.74 & 24.59 & 41.83 & 5.05 \\
\hline & Julio & 16.71 & 7.82 & 17.52 & 22.81 & 33.88 & 5.45 & & Julio & 18.68 & 7.75 & 18.96 & 25.37 & 41.02 & 4.83 \\
\hline & Agosto & 16.14 & 8.59 & 15.73 & 21.20 & 33.39 & 5.15 & & Agosto & 18.42 & 7.68 & 18.65 & 24.60 & 40.44 & 5.01 \\
\hline & Septiembre & 14.80 & 7.85 & 14.94 & 18.73 & 30.09 & 5.22 & & Septiembre & 17.87 & 8.39 & 18.61 & 24.34 & 37.30 & 4.97 \\
\hline & Octubre & 14.95 & 8.35 & 15.73 & 18.44 & 29.85 & 5.16 & & Octubre & 18.37 & 8.92 & 20.41 & 23.39 & 37.72 & 5.36 \\
\hline & Noviembre & 14.46 & 8.03 & 15.45 & 18.00 & 28.24 & 5.30 & & Noviembre & 17.03 & 7.96 & 18.85 & 20.98 & 35.65 & 5.19 \\
\hline & Diciembre & 12.76 & 6.72 & 14.03 & 15.93 & 23.87 & 5.63 & & Diciembre & 15.03 & 6.40 & 16.80 & 18.71 & 30.96 & 5.41 \\
\hline \multirow{12}{*}{  } & Enero & 15.36 & 6.91 & 18.66 & 17.88 & 29.22 & 6.90 & & Enero & 10.94 & 5.13 & 11.78 & 12.15 & 19.84 & 7.19 \\
\hline & Febrero & 14.66 & 6.86 & 17.19 & 16.26 & 27.54 & 7.64 & & Febrero & 9.86 & 4.90 & 10.00 & 10.91 & 17.46 & 7.14 \\
\hline & Marzo & 18.33 & 10.52 & 20.88 & 22.76 & 35.68 & 5.47 & & Marzo & 12.89 & 7.69 & 12.33 & 15.20 & 25.28 & 5.82 \\
\hline & Abril & 20.07 & 11.55 & 22.56 & 25.63 & 39.50 & 5.33 & & Abril & 12.69 & 7.90 & 11.59 & 14.36 & 25.86 & 5.35 \\
\hline & Mayo & 21.57 & 12.13 & 24.54 & 27.26 & 43.05 & 5.44 & & Mayo & 13.09 & 7.56 & 11.80 & 15.14 & 27.42 & 5.33 \\
\hline & Junio & 21.25 & 11.24 & 22.58 & 27.38 & 43.62 & 5.92 & $\overline{0}$ & Junio & 13.34 & 7.94 & 11.71 & 15.58 & 27.58 & 5.71 \\
\hline & Julio & 21.86 & 10.76 & 23.06 & 28.56 & 44.63 & 7.01 & $\stackrel{\infty}{<}$ & Julio & 12.65 & 7.24 & 12.00 & 14.41 & 25.51 & 5.79 \\
\hline & Agosto & 22.12 & 12.35 & 22.29 & 28.27 & 45.01 & 7.05 & & Agosto & 12.14 & 7.46 & 10.46 & 14.05 & 25.69 & 4.67 \\
\hline & Septiembre & 19.41 & 10.58 & 19.71 & 24.03 & 39.65 & 6.64 & & Septiembre & 12.06 & 7.41 & 10.90 & 13.81 & 24.68 & 5.08 \\
\hline & Octubre & 20.29 & 11.83 & 22.45 & 24.24 & 39.46 & 7.05 & & Octubre & 12.26 & 8.16 & 11.37 & 13.55 & 24.31 & 5.31 \\
\hline & Noviembre & 19.94 & 11.10 & 22.62 & 23.47 & 38.56 & 7.43 & & Noviembre & 11.73 & 7.42 & 10.33 & 13.45 & 23.40 & 5.50 \\
\hline & Diciembre & 16.94 & 9.12 & 19.30 & 19.75 & 31.79 & 7.53 & & Diciembre & 11.38 & 6.85 & 11.64 & 13.02 & 20.53 & 6.32 \\
\hline & Enero & 10.41 & 4.60 & 16.26 & 15.27 & 15.68 & 3.53 & & Enero & 11.40 & 5.14 & 12.69 & 13.02 & 21.36 & 6.50 \\
\hline & Febrero & 9.96 & 4.02 & 14.84 & 14.46 & 15.49 & 4.01 & & Febrero & 10.46 & 4.48 & 11.13 & 11.60 & 19.35 & 7.07 \\
\hline & Marzo & 10.70 & 5.02 & 13.35 & 16.03 & 20.59 & 1.84 & & Marzo & 13.06 & 6.88 & 12.76 & 15.84 & 26.35 & 5.62 \\
\hline & Abril & 11.04 & 5.62 & 12.66 & 16.16 & 22.11 & 1.80 & & Abril & 13.69 & 7.47 & 13.12 & 16.80 & 28.33 & 5.08 \\
\hline & Mayo & 11.89 & 5.39 & 12.98 & 18.77 & 24.61 & 1.55 & & Mayo & 14.66 & 7.56 & 14.16 & 17.51 & 31.33 & 5.22 \\
\hline : & Junio & 12.59 & 6.04 & 13.96 & 18.82 & 25.92 & 1.92 & $\sqrt{n}$ & Junio & 14.51 & 7.47 & 13.40 & 17.77 & 31.10 & 5.28 \\
\hline$\frac{5}{z}$ & Julio & 14.93 & 6.59 & 19.22 & 21.92 & 28.20 & 3.23 & نं & Julio & 14.96 & 7.19 & 14.60 & 18.36 & 31.18 & 6.13 \\
\hline & Agosto & 13.88 & 7.47 & 14.97 & 20.15 & 28.16 & 2.42 & & Agosto & 14.78 & 7.90 & 13.05 & 17.94 & 31.99 & 5.40 \\
\hline & Septiembre & 11.88 & 7.25 & 13.59 & 15.19 & 23.69 & 2.27 & & Septiembre & 13.78 & 7.34 & 12.85 & 16.50 & 28.95 & 5.47 \\
\hline & Octubre & 11.27 & 6.44 & 12.88 & 15.00 & 22.53 & 2.16 & & Octubre & 13.59 & 7.42 & 12.55 & 15.69 & 28.68 & 5.55 \\
\hline & Noviembre & 10.53 & 5.99 & 12.27 & 14.25 & 20.28 & 2.43 & & Noviembre & 13.27 & 7.30 & 12.32 & 15.11 & 27.42 & 6.00 \\
\hline & Diciembre & 10.46 & 5.70 & 14.02 & 15.60 & 17.07 & 3.04 & & Diciembre & 12.51 & 6.36 & 12.69 & 15.42 & 24.00 & 6.21 \\
\hline & Enero & 9.75 & 3.08 & 13.99 & 12.81 & 15.95 & 5.35 & & Enero & 11.54 & 4.80 & 14.20 & 14.02 & 21.01 & 5.90 \\
\hline & Febrero & 9.35 & 2.81 & 12.51 & 12.15 & 15.41 & 6.02 & & Febrero & 11.03 & 4.81 & 13.42 & 13.05 & 19.74 & 6.11 \\
\hline & Marzo & 11.68 & 4.01 & 13.64 & 16.88 & 22.50 & 4.60 & & Marzo & 12.11 & 6.01 & 12.93 & 15.43 & 24.27 & 4.38 \\
\hline 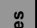 & Abril & 11.52 & 4.00 & 13.38 & 16.93 & 22.38 & 4.18 & & Abril & 12.47 & 5.89 & 12.74 & 15.76 & 26.26 & 4.20 \\
\hline : & Mayo & 12.27 & 3.89 & 13.34 & 19.08 & 24.59 & 4.22 & & Mayo & 13.52 & 6.13 & 13.68 & 17.38 & 28.60 & 4.64 \\
\hline : & Junio & 11.82 & 3.73 & 11.60 & 18.03 & 24.40 & 4.72 & $m$ & Junio & 13.72 & 5.86 & 13.50 & 18.20 & 29.11 & 4.90 \\
\hline$\frac{\bar{\infty}}{0}$ & Julio & 13.01 & 3.83 & 13.80 & 19.90 & 25.43 & 5.85 & 0 & Julio & 14.55 & 5.40 & 15.49 & 19.69 & 30.38 & 5.28 \\
\hline$\frac{0}{8}$ & Agosto & 12.60 & 4.70 & 12.36 & 18.70 & 26.16 & 4.50 & & Agosto & 14.09 & 6.00 & 13.47 & 18.04 & 30.79 & 4.98 \\
\hline & Septiembre & 10.95 & 3.72 & 11.59 & 15.82 & 22.23 & 4.32 & & Septiembre & 13.15 & 5.99 & 12.92 & 16.28 & 28.31 & 4.72 \\
\hline & Octubre & 11.50 & 4.65 & 11.28 & 16.19 & 23.69 & 4.45 & & Octubre & 13.35 & 6.19 & 13.22 & 15.92 & 28.82 & 4.90 \\
\hline & Noviembre & 11.48 & 4.43 & 11.41 & 16.45 & 23.26 & 4.69 & & Noviembre & 12.76 & 5.76 & 13.18 & 15.49 & 26.87 & 4.84 \\
\hline & Diciembre & 10.34 & 3.68 & 11.87 & 14.38 & 19.25 & 5.09 & & Diciembre & 11.33 & 5.08 & 12.23 & 14.22 & 22.28 & 5.04 \\
\hline & Enero & 10.81 & 4.24 & 12.00 & 12.70 & 20.05 & 6.80 & & Enero & 11.92 & 4.77 & 14.45 & 14.64 & 22.98 & 5.20 \\
\hline & Febrero & 9.78 & 4.11 & 10.27 & 10.92 & 17.93 & 6.92 & & Febrero & 11.19 & 4.41 & 13.41 & 13.32 & 21.13 & 5.77 \\
\hline & Marzo & 11.63 & 5.63 & 11.52 & 13.90 & 23.21 & 5.74 & & Marzo & 13.51 & 6.40 & 14.97 & 16.96 & 27.69 & 4.33 \\
\hline & Abril & 11.41 & 5.64 & 11.03 & 13.35 & 23.83 & 4.96 & & Abril & 14.26 & 6.95 & 15.47 & 18.65 & 29.39 & 4.05 \\
\hline$\infty$ & Mayo & 11.01 & 5.24 & 10.78 & 13.40 & 22.93 & 4.58 & & Mayo & 14.20 & 6.56 & 14.68 & 19.34 & 30.11 & 3.71 \\
\hline$\sum_{\Phi}^{ \pm}$ & Junio & 12.42 & 5.57 & 11.59 & 15.58 & 25.80 & 5.76 & Q & Junio & 14.73 & 6.74 & 14.24 & 19.56 & 32.14 & 4.24 \\
\hline \% & Julio & 13.19 & 6.37 & 12.85 & 15.89 & 25.63 & 7.26 & D & Julio & 16.31 & 7.56 & 16.77 & 21.69 & 33.51 & 5.60 \\
\hline & Agosto & 12.63 & 6.42 & 11.48 & 14.30 & 25.84 & 6.69 & & Agosto & 15.87 & 8.32 & 15.41 & 20.48 & 33.08 & 5.23 \\
\hline & Septiembre & 12.32 & 6.11 & 11.35 & 14.08 & 24.51 & 7.14 & & Septiembre & 14.65 & 7.82 & 14.42 & 18.37 & 29.81 & 5.51 \\
\hline & Octubre & 12.24 & 6.15 & 11.79 & 13.77 & 24.60 & 6.46 & & Octubre & 14.61 & 7.89 & 15.18 & 17.56 & 29.49 & 5.46 \\
\hline & Noviembre & 12.20 & 5.66 & 11.92 & 13.74 & 24.36 & 6.93 & & Noviembre & 13.49 & 7.23 & 14.13 & 16.00 & 27.06 & 5.32 \\
\hline & Diciembre & 11.15 & 5.59 & 11.30 & 12.78 & 20.36 & 7.18 & & Diciembre & 11.94 & 6.07 & 12.74 & 14.34 & 22.81 & 5.73 \\
\hline
\end{tabular}

Nota: Efectos de interacción estadísticamente significativos al $1 \%$ en negritas; efectos de interacción estadísticamente significativos al $5 \%$ en cursivas 
Revista Mad. No.7. Septiembre 2002. Departamento de Antropología. Universidad de Chile http://rehue.csociales.uchile.cl/publicaciones/mad/07/paper07.pdf

Cuadro 2.5: RatingPromedio Anual por Grupos Sociodemográficos Según Días de la Semana y Franjas

\begin{tabular}{|c|c|c|c|c|c|c|c|c|c|c|c|c|c|c|c|}
\hline & & $\begin{array}{c}\text { Promedio } \\
\text { Día }\end{array}$ & Matinal & $\begin{array}{l}\text { Mediodía / } \\
\text { Sobremesa }\end{array}$ & Vespertino & Prime Time & Trasnoche & & & $\begin{array}{c}\text { Promedio } \\
\text { Día }\end{array}$ & Matinal & $\begin{array}{l}\text { Mediodía / } \\
\text { Sobremesa }\end{array}$ & Vespertino & Prime Time & Trasnoche \\
\hline \multirow{7}{*}{ 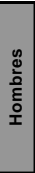 } & Lunes & 12.11 & 5.65 & 11.43 & 13.45 & 26.67 & 5.04 & \multirow{7}{*}{$\frac{n}{\frac{0}{3}}$} & \multirow{2}{*}{\begin{tabular}{|l|} 
Lunes \\
Martes
\end{tabular}} & 13.98 & 7.91 & 13.03 & 14.57 & 30.10 & 5.82 \\
\hline & Martes & 12.20 & 5.96 & 11.35 & 13.81 & 26.46 & 5.15 & & & 14.28 & 8.74 & 13.29 & 14.67 & 30.11 & 5.97 \\
\hline & Miércoles & 12.15 & 6.21 & 11.01 & 13.60 & 26.52 & 5.05 & & Miércoles & 14.36 & 8.91 & 13.19 & 14.76 & 30.39 & 5.94 \\
\hline & Jueves & 11.65 & 6.09 & 10.87 & 13.12 & 24.89 & 4.86 & & Jueves & 14.04 & 9.06 & 13.19 & 14.47 & 29.15 & 5.71 \\
\hline & Viernes & 11.65 & 6.16 & 11.00 & 12.77 & 23.52 & 6.15 & & Viernes & 13.95 & 8.93 & 12.70 & 13.76 & 27.75 & 7.57 \\
\hline & Sábado & 11.43 & 4.61 & 11.02 & 14.95 & 21.89 & 6.83 & & Sábado & 11.99 & 4.35 & 9.35 & 15.28 & 24.36 & 8.46 \\
\hline & Domingo & 12.51 & 4.43 & 12.50 & 16.84 & 26.89 & 4.80 & & Domingo & 12.96 & 4.40 & 11.06 & 17.15 & 29.45 & 5.43 \\
\hline \multirow{7}{*}{ 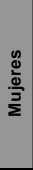 } & Lunes & 15.12 & 7.76 & 16.71 & 19.00 & 30.62 & 4.62 & \multirow{7}{*}{ 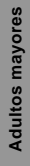 } & Lunes & 17.68 & 8.23 & 19.95 & 21.48 & 37.56 & 4.77 \\
\hline & Martes & 15.45 & 8.52 & 17.40 & 19.60 & 30.23 & 4.69 & & Martes & 18.31 & 9.13 & 21.27 & 22.40 & 37.67 & 4.86 \\
\hline & Miércoles & 15.64 & 8.67 & 17.53 & 19.68 & 30.69 & 4.81 & & Miércoles & 18.52 & 9.18 & 20.71 & 22.48 & 38.93 & 4.99 \\
\hline & Jueves & 15.42 & 8.74 & 17.35 & 19.36 & 30.12 & 4.65 & & Jueves & 17.98 & 9.05 & 20.61 & 21.84 & 37.29 & 4.73 \\
\hline & Viernes & 15.62 & 8.81 & 17.19 & 18.93 & 29.86 & 6.10 & & Viernes & 18.16 & 8.53 & 20.15 & 21.78 & 37.84 & 5.97 \\
\hline & Sábado & 12.18 & 4.79 & 11.51 & 16.58 & 23.75 & 6.81 & & Sábado & 15.29 & 4.34 & 12.30 & 21.95 & 33.99 & 7.46 \\
\hline & Domingo & 12.16 & 4.22 & 11.79 & 16.90 & 26.72 & 4.13 & & Domingo & 15.07 & 4.53 & 13.68 & 22.77 & 34.63 & 4.08 \\
\hline \multirow{7}{*}{ 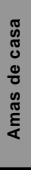 } & Lunes & 11.96 & 5.55 & 14.27 & 17.11 & 23.95 & 2.32 & \multirow{7}{*}{$\begin{array}{l}\bar{\delta} \\
\text { m }\end{array}$} & Lunes & 12.32 & 7.09 & 11.40 & 13.65 & 25.68 & 5.30 \\
\hline & Martes & 11.81 & 5.59 & 14.07 & 18.15 & 22.82 & 2.13 & & Martes & 12.41 & 7.80 & 11.52 & 14.01 & 25.13 & 5.17 \\
\hline & Miércoles & 12.07 & 5.94 & 14.33 & 18.13 & 23.35 & 2.24 & & Miércoles & 12.58 & 7.97 & 11.71 & 13.90 & 25.30 & 5.50 \\
\hline & Jueves & 11.60 & 5.55 & 13.74 & 17.73 & 22.35 & 2.21 & & Jueves & 12.13 & 7.86 & 11.10 & 13.41 & 24.44 & 5.23 \\
\hline & \multirow{3}{*}{$\begin{array}{l}\text { Viernes } \\
\text { Sábado } \\
\text { Domingo }\end{array}$} & 12.58 & 6.58 & 15.08 & 17.94 & 23.57 & 3.13 & & Viernes & 12.21 & 7.86 & 11.39 & 13.59 & 23.15 & 6.41 \\
\hline & & 10.99 & 6.78 & 14.75 & 14.61 & 18.03 & 3.43 & & \multirow{2}{*}{$\begin{array}{l}\text { Sábado } \\
\text { Domingo }\end{array}$} & 11.08 & 5.77 & 10.74 & 14.12 & 19.49 & 7.08 \\
\hline & & 10.48 & 5.00 & 13.59 & 14.11 & 20.39 & 2.10 & & & 11.97 & 5.71 & 11.51 & 14.07 & 24.77 & 5.65 \\
\hline \multirow{7}{*}{  } & Lunes & 11.96 & 5.55 & 14.27 & 17.11 & 23.95 & 2.32 & \multirow{7}{*}{ ชิ } & Lunes & 13.83 & 7.31 & 13.34 & 16.02 & 29.19 & 5.39 \\
\hline & Martes & 11.81 & 5.59 & 14.07 & 18.15 & 22.82 & 2.13 & & Martes & 13.81 & 7.68 & 13.35 & 15.89 & 28.93 & 5.22 \\
\hline & Miércoles & 12.07 & 5.94 & 14.33 & 18.13 & 23.35 & 2.24 & & Miércoles & 13.94 & 7.80 & 13.35 & 16.02 & 29.22 & 5.35 \\
\hline & Jueves & 11.60 & 5.55 & 13.74 & 17.73 & 22.35 & 2.21 & & Jueves & 13.56 & 7.81 & 13.21 & 15.95 & 27.84 & 5.11 \\
\hline & Viernes & 12.58 & 6.58 & 15.08 & 17.94 & 23.57 & 3.13 & & Viernes & 13.70 & 7.94 & 13.27 & 15.25 & 26.95 & 6.77 \\
\hline & Sábado & 10.99 & 6.78 & 14.75 & 14.61 & 18.03 & 3.43 & & Sábado & 12.11 & 5.00 & 11.58 & 15.86 & 22.85 & 7.50 \\
\hline & Domingo & 10.48 & 5.00 & 13.59 & 14.11 & 20.39 & 2.10 & & Domingo & 12.90 & 4.69 & 12.60 & 16.95 & 27.87 & 5.18 \\
\hline \multirow{7}{*}{ 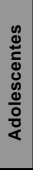 } & Lunes & 12.05 & 4.07 & 13.10 & 17.51 & 24.35 & 4.50 & \multirow{7}{*}{ ช } & Lunes & 13.17 & 5.82 & 13.83 & 16.02 & 28.20 & 4.49 \\
\hline & Martes & 12.13 & 4.22 & 13.14 & 17.96 & 24.34 & 4.40 & & Martes & 13.33 & 6.36 & 14.36 & 16.45 & 27.44 & 4.66 \\
\hline & Miércoles & 12.06 & 4.49 & 13.40 & 18.05 & 23.44 & 4.40 & & Miércoles & 13.45 & 6.59 & 14.33 & 16.45 & 27.83 & 4.62 \\
\hline & Jueves & 11.73 & 4.45 & 13.09 & 16.96 & 22.91 & 4.42 & & Jueves & 13.25 & 6.68 & 14.46 & 16.09 & 27.03 & 4.49 \\
\hline & Viernes & 11.76 & 4.60 & 13.57 & 16.63 & 20.95 & 5.97 & & Viernes & 13.30 & 6.60 & 14.06 & 15.83 & 26.28 & 5.97 \\
\hline & Sábado & 9.55 & 2.86 & 10.94 & 13.62 & 16.93 & 5.80 & & Sábado & 11.29 & 3.93 & 11.01 & 15.38 & 22.09 & 6.46 \\
\hline & Domingo & 10.31 & 2.52 & 10.75 & 14.56 & 22.08 & 4.31 & & Domingo & 11.89 & 3.67 & 11.87 & 16.82 & 25.95 & 4.22 \\
\hline \multirow{7}{*}{  } & Lunes & 12.19 & 5.68 & 11.66 & 13.78 & 25.57 & 5.96 & & Lunes & 14.35 & 7.02 & 15.70 & 17.53 & 29.71 & 4.59 \\
\hline & Martes & 12.37 & 6.10 & 11.96 & 14.01 & 25.08 & 6.37 & & Martes & 14.78 & 7.62 & 16.11 & 18.45 & 29.80 & 4.84 \\
\hline & Miércoles & 12.16 & 6.29 & 11.70 & 13.40 & 24.65 & 6.26 & & Miércoles & 14.77 & 7.86 & 15.84 & 18.25 & 29.99 & 4.74 \\
\hline & Jueves & 12.03 & 6.47 & 11.73 & 13.34 & 24.08 & 6.03 & 口 & Jueves & 14.33 & 7.76 & 15.56 & 17.66 & 28.81 & 4.61 \\
\hline & Viernes & 11.42 & 6.30 & 11.20 & 12.54 & 21.41 & 6.91 & & Viernes & 14.46 & 7.93 & 15.69 & 17.19 & 28.18 & 5.78 \\
\hline & Sábado & 10.36 & 4.15 & 10.37 & 13.69 & 18.13 & 7.37 & & Sábado & 12.24 & 4.78 & 11.51 & 16.51 & 24.29 & 6.63 \\
\hline & Domingo & 11.68 & 4.01 & 11.87 & 15.26 & 24.03 & 5.67 & & Domingo & 12.42 & 4.20 & 12.23 & 17.64 & 27.39 & 3.87 \\
\hline
\end{tabular}

Nota: Efectos de interacción estadísticamente significativos al $1 \%$ en negritas; efectos de interacción estadísticamente significativos al $5 \%$ en cursivas 


\begin{abstract}
Cuadro 2.6: Distribución del 10\% Más Alto y Más Bajo de Promedios Anuales de Rating en Franjas Prime Time, Noticiero y Primera Serie Según Fechas
\end{abstract}

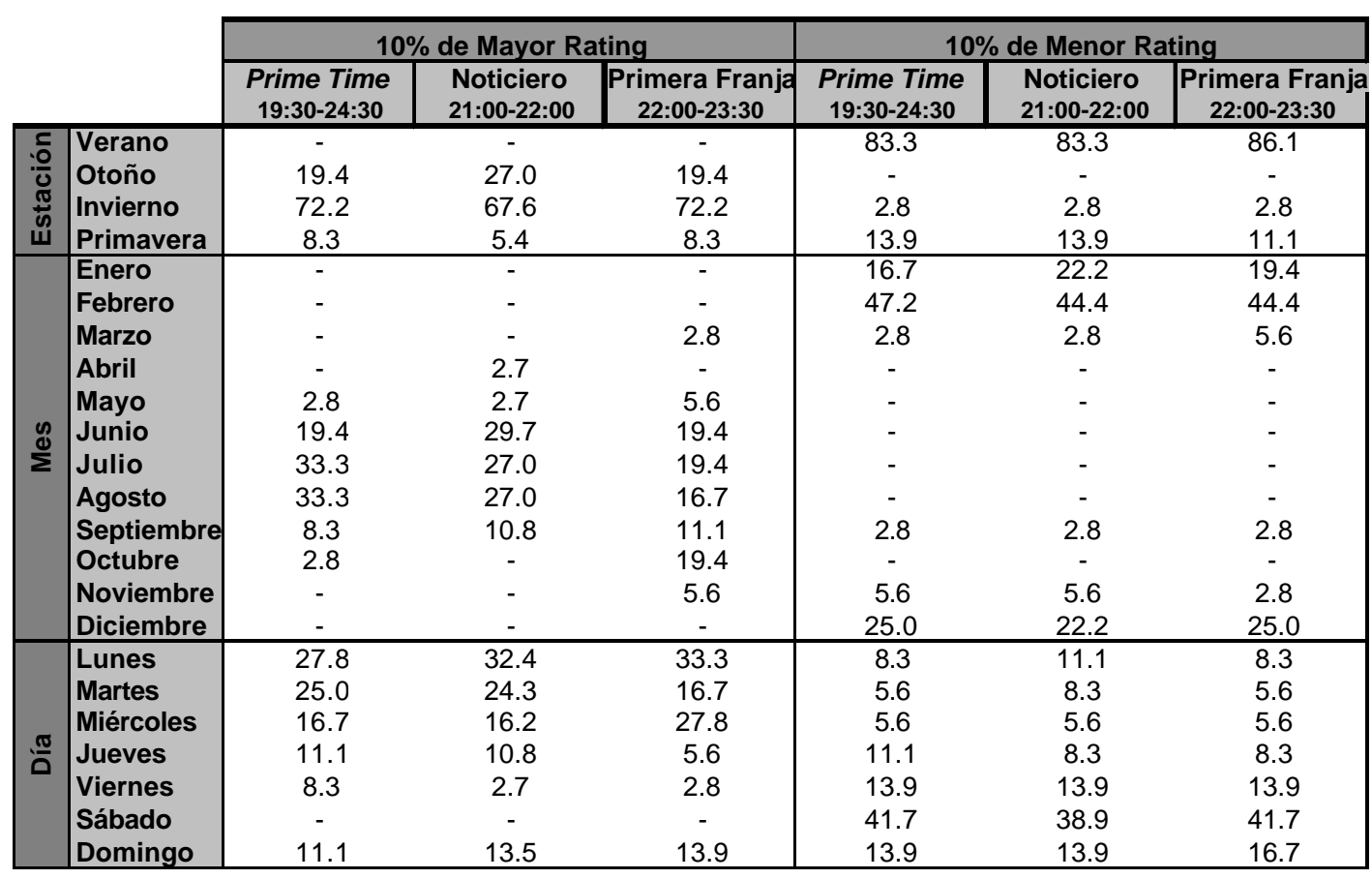


Cuadro 2.7: Coeficiente de Variación de Rating en Franjas Prime Time, Noticiero y Primera Serie Según Agrupaciones de Días

\begin{tabular}{|l|c|c|c|}
\cline { 2 - 4 } \multicolumn{1}{c|}{} & $\begin{array}{c}\text { Prime Time } \\
\text { 19:30-24:30 }\end{array}$ & $\begin{array}{c}\text { Noticiero } \\
\mathbf{2 1 : 0 0 - 2 2 : 0 0}\end{array}$ & $\begin{array}{c}\text { Primera Franja } \\
\mathbf{2 2 : 0 0 - 2 3 : 3 0}\end{array}$ \\
\hline Todos los Días del Año & 0.1687 & 0.2213 & 0.1643 \\
\hline Lunes - Viernes & 0.1530 & 0.2071 & 0.1452 \\
\hline Lunes - Jueves & 0.1498 & 0.2032 & 0.1417 \\
\hline $\begin{array}{l}\text { Lunes - Jueves Sin Feriados } \\
\text { o Vísperas de Feriados }\end{array}$ & 0.1389 & 0.1961 & 0.1251 \\
\hline
\end{tabular}

\section{Cuadro 2.8: Coeficientes de Variación de Rating en Franjas Prime Time, Noticiero y Primera Franja de Días Usuales Lunes - Jueves Según Fechas}

\begin{tabular}{|c|c|c|c|c|}
\hline & & $\begin{array}{c}\text { Prime Time } \\
\text { 19:30-24:30 } \\
\end{array}$ & $\begin{array}{l}\text { Noticiero } \\
\text { 21:00-22:00 } \\
\end{array}$ & \begin{tabular}{|c|} 
Primera Franja \\
$22: 00-23: 30$
\end{tabular} \\
\hline & AÑO 2001 & 0.1389 & 0.1961 & 0.1251 \\
\hline \multirow{4}{*}{$\begin{array}{l}: \text { 응 } \\
\mathbb{\varpi} \\
\text { w }\end{array}$} & Verano & 0.1340 & 0.1721 & 0.1240 \\
\hline & Otoño & 0.0542 & 0.0653 & 0.0563 \\
\hline & Invierno & 0.0479 & 0.0549 & 0.0548 \\
\hline & Primavera & 0.0864 & 0.1511 & 0.0901 \\
\hline \multirow{12}{*}{$\sum^{\mathscr{E}}$} & Enero & 0.0794 & 0.0914 & 0.0849 \\
\hline & Febrero & 0.1134 & 0.1125 & 0.1297 \\
\hline & Marzo & 0.0837 & 0.1073 & 0.0854 \\
\hline & Abril & 0.0506 & 0.0618 & 0.0555 \\
\hline & Mayo & 0.0367 & 0.0306 & 0.0497 \\
\hline & Junio & 0.0317 & 0.0278 & 0.0405 \\
\hline & Julio & 0.0423 & 0.0541 & 0.0375 \\
\hline & Agosto & 0.0499 & 0.0539 & 0.0557 \\
\hline & Septiembre & 0.0552 & 0.0656 & 0.0693 \\
\hline & Octubre & 0.0577 & 0.0554 & 0.0613 \\
\hline & Noviembre & 0.0559 & 0.1012 & 0.0526 \\
\hline & Diciembre & 0.0566 & 0.0853 & 0.0808 \\
\hline \multirow{4}{*}{ 类 } & Lunes & 0.1354 & 0.1872 & 0.1182 \\
\hline & Martes & 0.1358 & 0.1922 & 0.1173 \\
\hline & Miércoles & 0.1396 & 0.2010 & 0.1257 \\
\hline & Jueves & 0.1413 & 0.2053 & 0.1296 \\
\hline
\end{tabular}




\section{Notas}

1) Véase Tercera Encuesta Nacional de Televisión, CNTV, 2000.

2) Un esquema similar es desarrollado por Casetti y Di Chio (1999: 19-43). Estos autores hablan de tres núcleos temáticos básicos del análisis televisivo: "la producción de cuanto está destinado a aparecer en la pequeña pantalla; la oferta televisiva, es decir, los programas en concreto [...] y en conjunto y el consumo de todo lo que nos ofrece la televisión" (1999:20).

3) En este estudio, salvo cuando se indique lo contrario, utilizaremos la definición que entrega el sistema People Meter por defecto, el cual genera un registro de la exposición "siempre y cuando ésta tenga una duración mínima de 30 segundos" (Time-lbope, 1998: 38).

4) En Chile la medición de las audiencias televisivas estuvo basada en el método recordatorio hasta principios de la década de los noventa.

5) En España la muestra de la empresa Sofres llega a 3.105 hogares y 10.029 individuos (Jauset, 2000: 191). En Italia, Auditel estudia a 5.000 hogares y 15.000 individuos (Cassetti y Di Chio 1999:60). Nielsen, por su parte, elaboró una muestra nacional en EE.UU. de 5000 hogares y 11.000 personas y de 2.100 hogares y 5.500 personas en Canadá. (Nielsen Media Research 2000:6)

6) En conversación con el autor.

7) La inversión en televisión abierta por parte de los avisadores en Chile alcanzó el año 1999 los 80 mil millones de pesos. (La Tercera, 23/12/99). Actualmente, se calcula que el $43 \%$ de la inversión en publicidad se realiza en televisión (Revista Network Market, №15, año 2).

8) En opinión de Víctor Saldías, analista de Time-lbope, mientras los canales de televisión se concentran exclusivamente en los índices de audiencia a nivel hogares, las agencias de publicidad se preocupan de mayor modo por los índices individuales.

9) La medición del comportamiento frente a la televisión por cable se incluyó desde principios del año 2001.

10) Siguiendo la recomendación de algunos investigadores que han trabajado con datos provenientes del sistema People Meter, este estudio no combinará más de una variable sociodemográfica a la vez. Al respecto, Flavio Cortés señala: "El reducido tamaño de la muestra (300 hogares, en un primer momento) resulta insuficiente para detectar comportamientos de subpoblaciones como las que se constituyen cuando se segmenta a la población por más de dos ó tres características sociodemográficas simultáneamente" (Toloza y Lahera, 1997:596).

11) Este índice incorpora, asimismo, el uso del televisor para la reproducción de cintas de video y para consolas de juegos, actividades que, sin embargo, resultan marginales frente a la magnitud de la recepción de señales de televisión.

12) En conversación personal con el autor.

13) Recuérdese que el rating total es el resultado de una ponderación del rating de los diversos grupos a partir del peso de sus características sociodemográficas básicas y otras tales como la posesión de televisión por cable. 
14) Se define como la persona integrante del hogar que cotidianamente toma las decisiones de compra para el cuidado y mantención de la familia. En términos operacionales puede ser desempeñado por un hombre o una mujer.

15) Recuérdese que los datos analizados en este capítulo se agruparon originalmente en períodos de 15 minutos. 